Filipe, V. (2020): “Las ánforas romanas más antiguas del occidente peninsular en Olisipo (Lisboa): contribución a su estudio", Spal 29.2: 179-204. DOI: https://dx.doi.org/10.12795/spal.2020.i29.23

\title{
LAS ÁNFORAS ROMANAS MÁS ANTIGUAS DEL OCCIDENTE PENINSULAR EN OLISIPO (LISBOA): CONTRIBUCIÓN A SU ESTUDIO
}

\section{AS MAIS ANTIGAS ÂNFORAS ROMANAS DO OCIDENTE PENINSULAR EM OLISIPO (LISBOA): CONTRIBUTO PARA O SEU ESTUDO}

\author{
VICTOR FILIPE \\ UNIARQ - Centro de Arqueologia da Universidade de Lisboa, Faculdade de Letras \\ victor.filipe7@gmail.com (D) https://orcid.org/0000-0003-4356-5442 \\ ResearcherID: https://publons.com/researcher/AAG-2008-2019
}

Resumen: La producción de ánforas con características morfológicas totalmente romanas en el occidente de la Península ha sido documentada desde el tercer cuarto del siglo I a.C., es decir, desde los últimos momentos de la República. Sin embargo, y a pesar del importante desarrollo que su estudio ha experimentado en los últimos quince años, el conocimiento que tenemos actualmente sobre los contenedores producidos entre esa fase y el tercer cuarto del siglo I d.C. todavía es bastante reducido. El objetivo de este estudio es presentar un conjunto significativo de nuevos datos de la ciudad romana de Lisboa, que es, por el momento, el principal centro de consumo de estas producciones. Enmarcado en el estado actual de la investigación y en las principales problemáticas subyacentes a este tema, se busca establecer las posibles lecturas sobre la diacronía de producción y circulación de estas ánforas, así como su significado en el contexto del consumo de alimentos transportados en contenedores anfóricos en Olisipo.

Palabras claves: Republica Romana, Alto Imperio, Comercio, Hispania Ulterior, Lusitania

\begin{abstract}
The production of amphorae with fully Roman morphologic characteristics in the western Peninsula started in the third quarter of the $1^{\text {st }} \mathrm{c}$. B.C., that is, in the final moments of the Republic. However, despite the important development of its study over the last fifteen years, the knowledge currently held on containers produced between that period and the third quarter of the $1^{\text {st }}$ c. A.D. is still quite limited. This study aims to present a significant set of new data from the Roman city of Olisipo, which represents, for the time being, the main consumption centre of these amphoric productions. Framed in the current state of research and in the main issues underlying this theme, we seek to establish the possible readings about the production and circulation chronology of these amphorae, as well as their meaning in the context of the consumption of foodstuffs transported in amphoric containers in the Roman city of Lisbon.
\end{abstract}

Keywords: Roman Republic, Principate, Roman trade, Hispania Ulterior, Lusitania 


\section{INTRODUCCIÓN}

En los últimos años ha habido un avance significativo en el estudio de las producciones anfóricas romanas más antiguas en el occidente de la península ibérica. Sin embargo, y a pesar de este aumento consistente de los datos disponibles, la caracterización de estas ánforas se encuentra todavía en un estado algo incipiente en casi todos los aspectos de su estudio, en particular en lo que respecta a cuestiones de tipología, cronología y centros productores.

Esta realidad se debe principalmente a tres factores: la generalidad de los materiales documentados está compuesta por pequeños fragmentos de borde, con muy pocos ejemplares completos o semi-completos; escasez de datos contextuales; y profundo desconocimiento sobre los centros alfareros.

Estas producciones incluyen ánforas con una morfología claramente ovoide (Ovoides Lusitanas, Morais y Filipe 2016), consideradas como las formas más antiguas, pero también alargadas y fusiformes, más cercanas al universo de las Dressel 7-11 y Haltern 70 (Morais 2003, Morais y Filipe 2016, Almeida y Fabião 2019). Aunque este último tipo esté relativamente bien caracterizado en cuanto a su morfología (Filipe 2016), conociéndose dos ejemplares completos (Diogo 2005, Quaresma 2005), de las formas ovoides y con bordes claramente inspirados en las Dressel 7-11 se desconocen piezas completas, lo que, unido a la multiplicidad de variantes de borde, no nos permite definir con seguridad si nos enfrentamos a diferentes tipos o simplemente a producciones con un bajo nivel de estandarización.

En general, estas ánforas tienen bordes moldurados o en banda, con una mayor o menor inclinación hacia el exterior, y cuellos y asas normalmente cortos, características que los diferencian del tipo Dressel 14.

Actualmente, bajo la designación genérica de Lusitanas Antiguas, se agrupan las ánforas que se ajustan claramente dentro de las características arriba mencionadas de las producciones más antiguas del occidente peninsular, incluyendo aquí también las formas potencialmente clasificables en la Lusitana 12 de A. Dias Diogo (1987) y en la designada Dressel 14A del Sado (Mayet y Silva 1998, Mayet y Silva 2002).

En Lisboa, ya se conocían algunos datos importantes sobre esas producciones, especialmente en el Teatro Romano (Filipe 2008a, Filipe 2015), en la Rua dos Bacalhoeiros (Filipe 2008b), en la Rua dos Remédios y en la Praça da Figueira (Silva 2015, Silva et al. 2016).
El reciente estudio sobre las ánforas republicanas e imperiales de Olisipo (Filipe 2019) ha revelado nuevos e importantes datos sobre la comercialización de estas ánforas en la ciudad, que actualmente corresponden al conjunto más grande de estos contenedores conocido en el territorio portugués. En este trabajo se presentan esos datos, que son particularmente relevantes para la definición de la cronología, el volumen y la proporción de esas producciones, buscando así contribuir a la evolución del conocimiento sobre estas producciones anfóricas.

\section{LAS MÁS ANTIGUAS ÁNFORAS ROMANAS DEL OCCIDENTE PENINSULAR: ESTADO DE LA CUESTIÓN}

Aunque la referencia a una antigua producción de contenedores anfóricos en el espacio geográfico que ocuparía la provincia de Lusitania se remonta a los años ochenta del siglo pasado (Diogo 1987), fue Rui Morais (2004) quien se encargó de destacar, por primera vez de manera sólida, la existencia de una producción de ánforas de morfología ovoide en el período republicano tardío, con una difusión considerable y cuantitativamente expresiva.

El aludido investigador se fundamentó, al momento, en conjuntos de ánforas ovoides, de evidente fabricación lusitana, exhumadas en contextos datados entre mediados y finales del siglo I a.C., documentados en varios sitios en Galicia (Castro de Panxón, Montecastro y Castro de Vigo - Vigo), en la región entre los ríos Duero e Miño (Castro de Santa Luzia y Castro da Terronha, Viana do Castelo; Rua da Banharia e Aljube, Porto), en el Castro de Fiães, Vila da Feira, y en el Castelo da Lousa, Mourão (Morais 2003: 40).

\subsection{Cronología}

La producción de estos contenedores, que constituyen las ánforas más antiguas de morfología plenamente romana fabricadas en el extremo occidental de la Península, parece haber comenzado en el tercer cuarto del siglo I a.C. con la fabricación de contenedores con forma tendente a ovoide y bordes moldurados o en banda, inspirados en los modelos del sur de la Península y, eventualmente, de la costa adriática de la península itálica, perdurando hasta el tercer cuarto de siglo I d.C. (Morais 2003: 36-40, Morais y Fabião 2007: 131-132, Fabião 2008: 726, Morais 2010: 190-191, 
Filipe 2008a, Filipe 2015: 146-147, Filipe 2016, Mataloto et al. 2016: 146, Morais y Filipe 2016, Silva et al. 2016: 164, Pimenta 2017: 203).

Además del Castelo da Lousa y de los sitios del Noroeste mencionados, las ánforas de esta fase inicial de la producción también aparecen en contextos anteriores al cambio de Era en sitios como el Monte dos Castelinhos (Pimenta 2017: 203), Pedrão (Mayet y Silva 2016: 64), Rocha da Mina, Alandroal (Mataloto y Roque 2013: 136, Mataloto et al. 2016: 146), Caladinho (Mataloto et al. 2016: 148) y, posiblemente, en NARQ (Núcleo Arqueológico da Rua dos Correeiros), Lisboa, donde se registran en niveles genéricamente datados de entre 25 a.C. y 50 d.C. (Fabião et al. 2016: 109). Especialmente para esta fase más antigua, su ocurrencia parece coincidir, al menos en parte, con sitios con una presencia militar comprobada o integrantes del proceso de romanización y articulación del interior del territorio que, simultáneamente, coinciden con los circuitos de distribución de las ánforas da la Ulterior/Baetica de la segunda mitad del siglo I d.C. (García Vargas et al. 2011: 265, Almeida y Fabião 2019: 180).

\subsection{Tipología}

La caracterización cronotipológica de estas primeras producciones aún se encuentra en un incipiente estado de investigación, en gran parte debido a la escasez de buenas estratigrafías que permitan la definición de las fases diacrónicas de un conjunto muy diverso de perfiles de borde - que corresponderán, o no, a otras tantas formas -, así como a la escasez de piezas completas, necesarias para la correcta definición de los diferentes tipos y sus respectivas características morfológicas. Estas son muy cercanas a algunas formas producidas en la región sur de la península ibérica, a saber, Ovoide 1/Clase 67, Ovoide 4, Haltern 70 y el universo de las Dressel 7-11 (Arruda et al. 2006a, Morais y Fabião 2007, Pimenta 2015, Filipe 2016, Morais y Filipe 2016), como demuestran los ejemplares completos procedentes del río Tajo (Quaresma 2005: 419) y de la isla de Berlenga (Diogo 2005: 114), u otro depositado en el Museo de Évora (Morais y Fabião 2007: 128), este clasificable en la forma Lusitana 12 de A. Dias Diogo (1987) (fig. 1).

No obstante, los últimos años han sido fructíferos en la publicación de ejemplares que pueden enmarcarse en estas producciones, casi siempre limitadas a pequeños fragmentos de borde, fondo o asa y recurrentemente descontextualizadas. El conjunto significativo de datos actualmente conocidos permite atestiguar la presencia de una importante industria alfarera productora de ánforas en los valles del Tajo y del Sado, que no es más que el reflejo de una actividad piscícola relevante en esas regiones a partir del tercer cuarto de siglo I a.C., con peso suficiente para convertirse gradualmente, con toda probabilidad, en uno de los motores económicos más importantes del extremo occidental de la península ibérica, especialmente a partir del Principado de Augusto.

En el estado actual del conocimiento, la escasez de ejemplares completos o considerablemente conservados no permite definir si la multiplicidad de perfiles de bordes que conocemos hoy en día revela un bajo nivel de estandarización de estas ánforas o si, por el contrario, demuestra la existencia de un amplio repertorio tipológico en las producciones anfóricas de los valles de los ríos Tajo y Sado entre la segunda mitad del siglo I a.C. y el tercer cuarto del siglo siguiente, como ocurrió en el mismo período en la provincia de la Ulterior/Bética.

En términos generales, y como ya se ha mencionado, se observa una gran variedad en el diseño de los bordes, normalmente moldurados o en banda, con una mayor o menor inclinación hacia el exterior y un mayor o menor diámetro, con cuellos normalmente cortos y con tendencia cilíndrica o troncocónica, asas cortas, con sección ovalada, con o sin surco longitudinal en la espalda y digitación en su inicio inferior. También aparecen bocas similares a la Ovoide 1/Clase 67, con la presencia de un anillo bajo el borde, que puede ser redondeado, sub-rectangular o sub-triangular. El cuerpo es ovoide o de tendencia cilíndrica y los fondos suelen ser huecos o llenos con una bola de arcilla. En los primeros, el exterior puede presentarse liso o con una moldura de botón, mientras que las segundas normalmente exhiben características similares a las de los fondos de la Haltern 70 o algunas ánforas ovoides del Guadalquivir de la primera mitad del siglo I a.C. (Morais 2003: 40, Morais y Fabião 2007: 128-129, Filipe 2008a: 72, Filipe 2016, Morais y Filipe 2016). Cabe señalar también que estas primeras producciones atribuibles a los valles de los ríos Tajo y Sado suelen presentar engobes blanquecinos o beige, a veces bastante gruesos (fig. 2).

\subsection{Centros productores}

Hasta el momento, la producción de las designadas Lusitanas Antiguas está atestiguada en varios lugares del valle del Sado, que comenzaron a producir durante la 


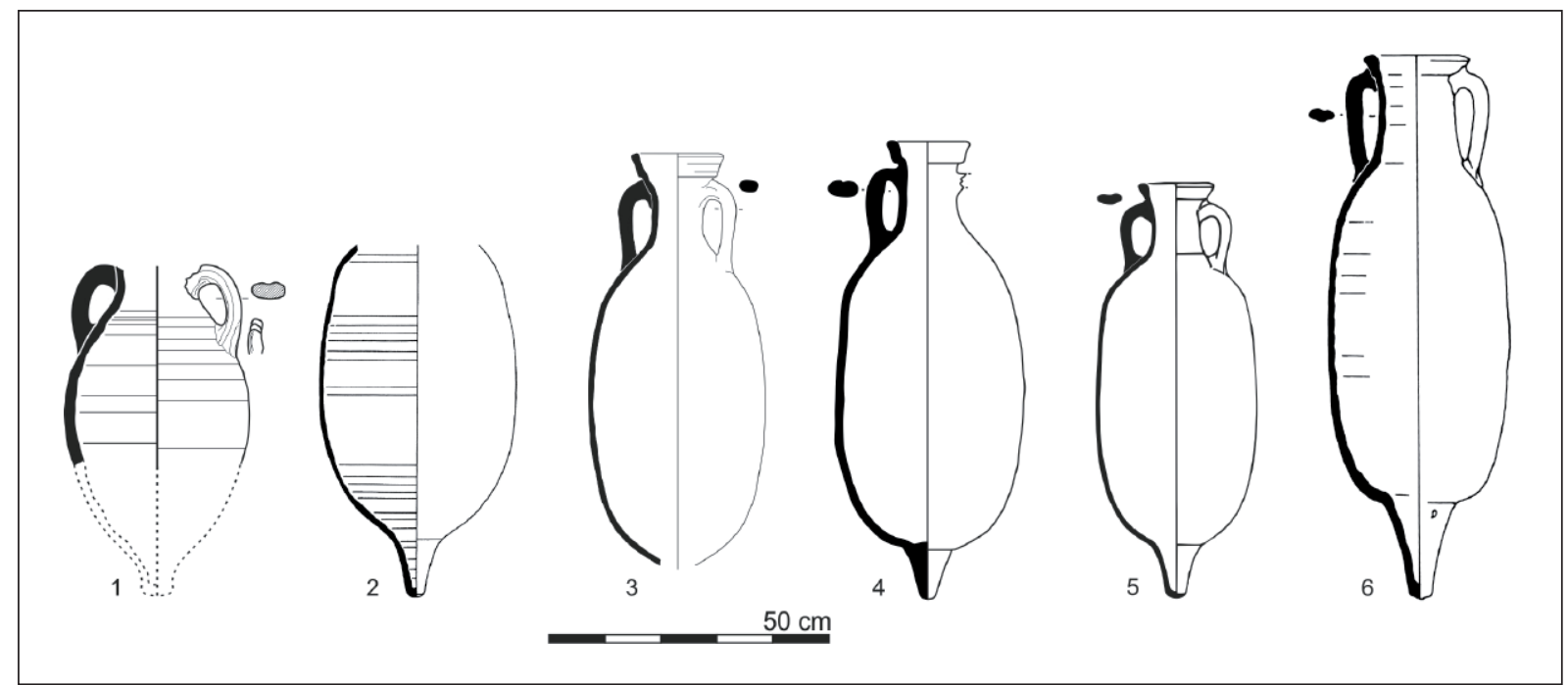

Figura 1. 1: Ovoide Lusitana, Aljube, Porto (Morais, 2003, fig. 34, $n^{\circ}$ 30); 2: Tipo indeterminado, Albergue distrital de Braga (Morais et al, 2016, fig. 1d); 3: Haltern 70 Lusitana, Rio Tejo, Vila Franca de Xira (Quaresma, 2005, est. 14); 4: Haltern 70 Lusitana, Ao largo da Berlenga (Diogo et al., 2005, fig. 5); 5: Lusitana 12, Museu de Évora (Diogo, 1987, fig. 7); 6: Dressel 14A, Abul (Mayet e Silva, 2002, fig. 46).

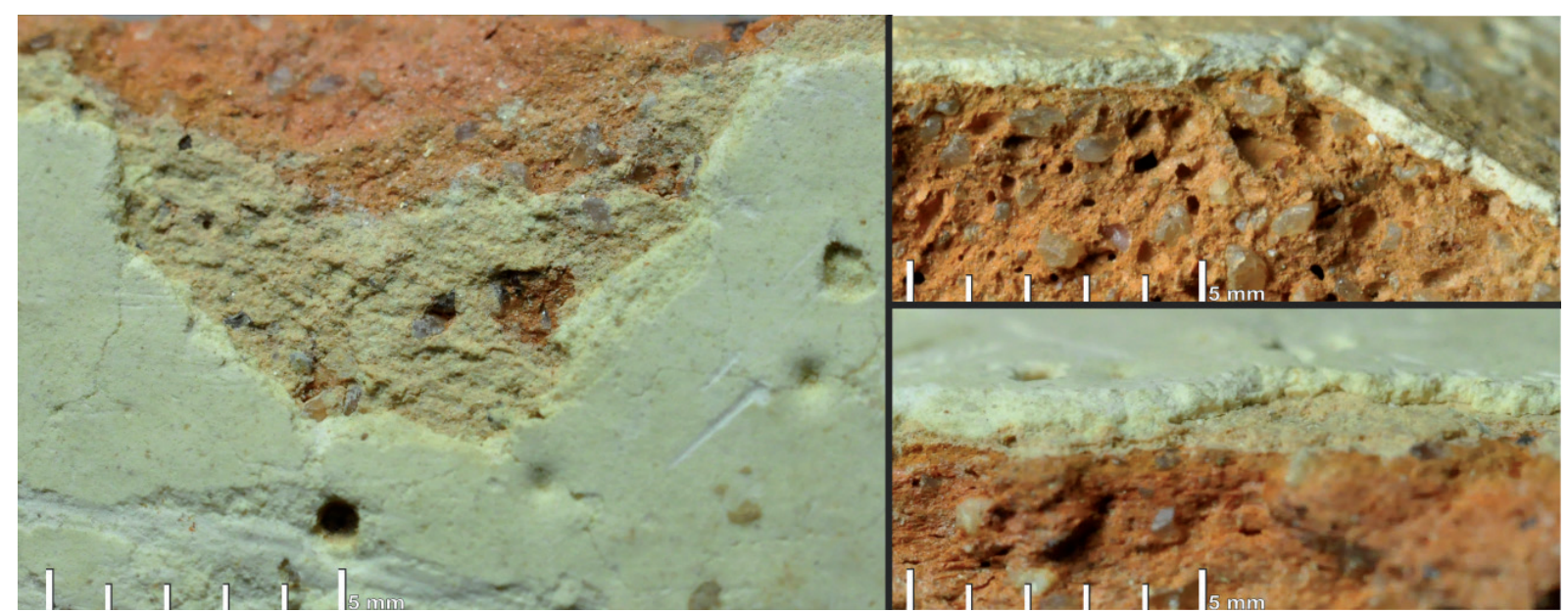

Figura 2. Pormenor sobre los engobes espesos, de color blanquecino.

dinastía julio-claudia, concretamente en el Largo da Misericórdia, en Setúbal (Silva 1996), en Pinheiro (Mayet y Silva 1998), en Abul (Mayet y Silva 2002) y en los Fornos da Parvoíce, Alcácer do Sal (Pimenta et al. 2016). Otro centro alfarero fue recientemente documentado en el centro histórico de Setúbal, en la calle António Joaquim Granjo (Mayet y Silva 2016), datando del período de Augusto, en el que, aunque no se hayan identificado los hornos, se ha registrado la presencia de ánforas con defectos de cocción, que pueden incluirse en las primeras producciones del occidente peninsular.
En el valle del Tajo, aunque seguramente también habrá existido la fabricación de ánforas en fases tan tempranas (Fabião 2008, Dias et al. 2012), nunca se ha excavado ninguna alfarería con una cronología de producción tan precoz, aunque los materiales recuperados en Muge son un fuerte indicio de su probable fabricación en ese lugar (Cardoso 1990). Aunque se inscriben en el mismo ámbito cronológico, las producciones de Peniche no se consideran en este estudio, ya que se trata de una realidad bien individualizada y demarcada de las producciones de los valles de los ríos Tajo y Sado, 

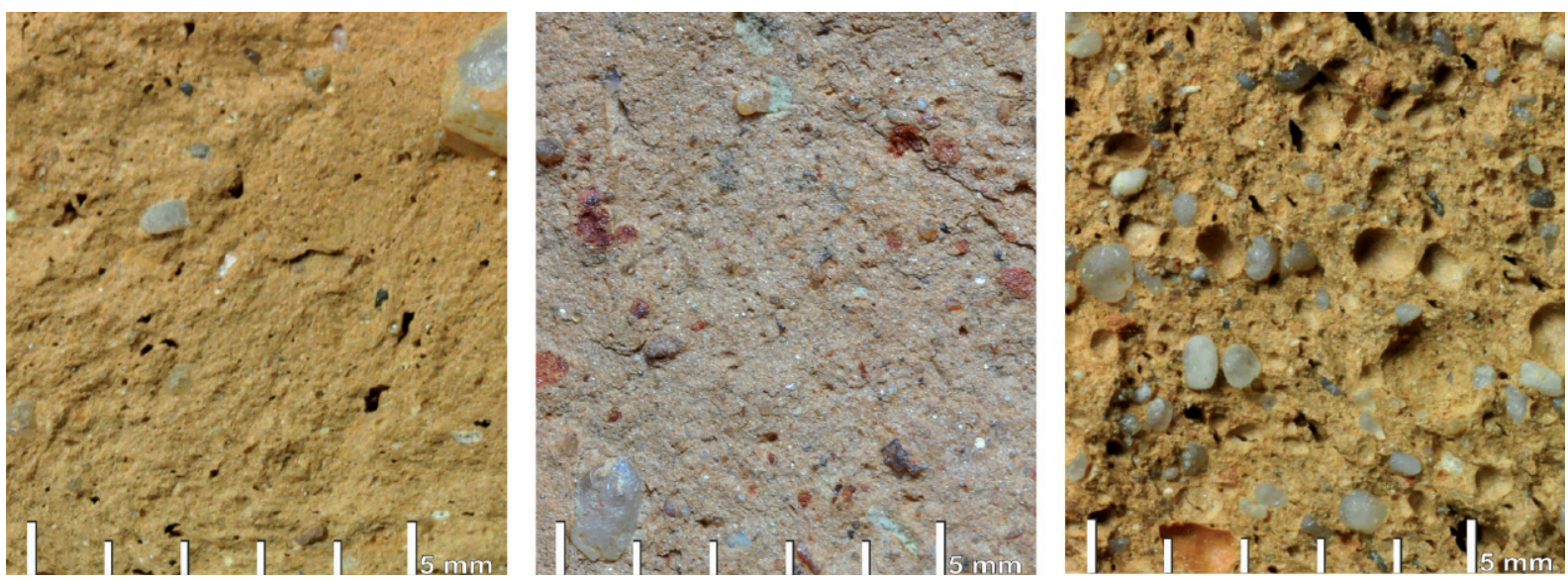

Figura 3. Algunos tipos de pastas documentadas en las ánforas Lusitanas Antiguas.

con referencia tanto a las formas como al tipo de pastas (Cardoso et al. 2006, 2016).

Considerando la cronología de los centros alfareros enumerados, será fácil comprender que hay varios centros más de producción aún desconocidos que habrán trabajado durante el periodo de tiempo en el que se produjeron estas formas, especialmente en los valles del Tajo y el Sado (Morais y Fabião 2007: 129). Esta lógica está en consonancia con el hecho de que en varios lugares hay ánforas con pastas innegablemente lusitanas pero de las que se desconoce el centro productor, como es el caso de Santarém (Arruda et al. 2006a: 237), del Teatro Romano de Lisboa (Filipe 2008a: 78) y del NARQ, Lisboa, en este caso confirmado con análisis químicos (Dias et al. 2012: 68), y del Castelo da Lousa (Morais y Fabião 2007: 129, Morais 2010: 191), evidenciando aquí una probable producción regional en Alentejo.

También en Algarve, al parecer, hubo producción de ánforas en etapas tempranas, concretamente del tipo Haltern 70, cuya cronología está por el momento determinada entre la época de Augusto y el reinado de Calígula, siendo su fabricación en esa región desconocida hasta hace poco y estando de momento documentada solo en Monte Molião (Arruda y Viegas 2016: 458-460).

No se comprueba una gran tradición epigráfica en los centros alfareros que fabricaron las ánforas romanas más antiguas de Lusitania, lo que no difiere mucho de lo que sucede en momentos posteriores, ya que solo se conoce una marca en uno de estos recipientes. Se trata de una pieza del NARQ que conserva el borde, el cuello y el inicio de las asas, clasificable como Haltern $70 \mathrm{Lu}-$ sitana. Incompleto en su parte final, el sello se puso en el cuello del contenedor, teniendo una tablilla rectangular donde se puede leer ROM [...] o POM [...] (Dias et al. 2012: 61, fig. 2, no 3460; Fabião et al. 2016: 109 y Est. 14, $\left.n^{\circ} 131\right)$.

\subsection{Contenido}

Aunque hasta la fecha hay pocas evidencias directas de los productos transportados por estas ánforas, es muy probable que estuvieran esencialmente destinadas a envasar preparados de pescado, ya que los lugares donde se fabricaron corresponden a regiones con excelentes condiciones para la explotación de los recursos marinos, como se ha documentado ampliamente desde mediados del siglo I d.C. Dicho contenido se demostró, al menos en parte de estas formas antiguas, en los análisis de residuos orgánicos realizados en contenedores del Castro de Vigo y de la ciudad de Braga (Oliveira et al. 2015, Morais et al. 2016). No obstante, creemos que la elevada posibilidad de otro contenido, como por ejemplo, el vino, debe mantenerse abierta, ya sea porque una de las formas producidas imita un recipiente que se utilizaría para transportar este producto - la Haltern 70 - o por la existencia de una tradición de producción de vino y de ánforas vinarias en estas mismas regiones, probada desde principios del siglo II d.C. (Filipe 2016).

Por estas razones, se considera plausible un contenido de pescado para las producciones lusitanas más antiguas, con la excepción de la Haltern 70 que, según la alta posibilidad de un contenido vinario (aunque no está atestiguado), se ha preferido considerar como de contenido indeterminado. También hay que mencionar 


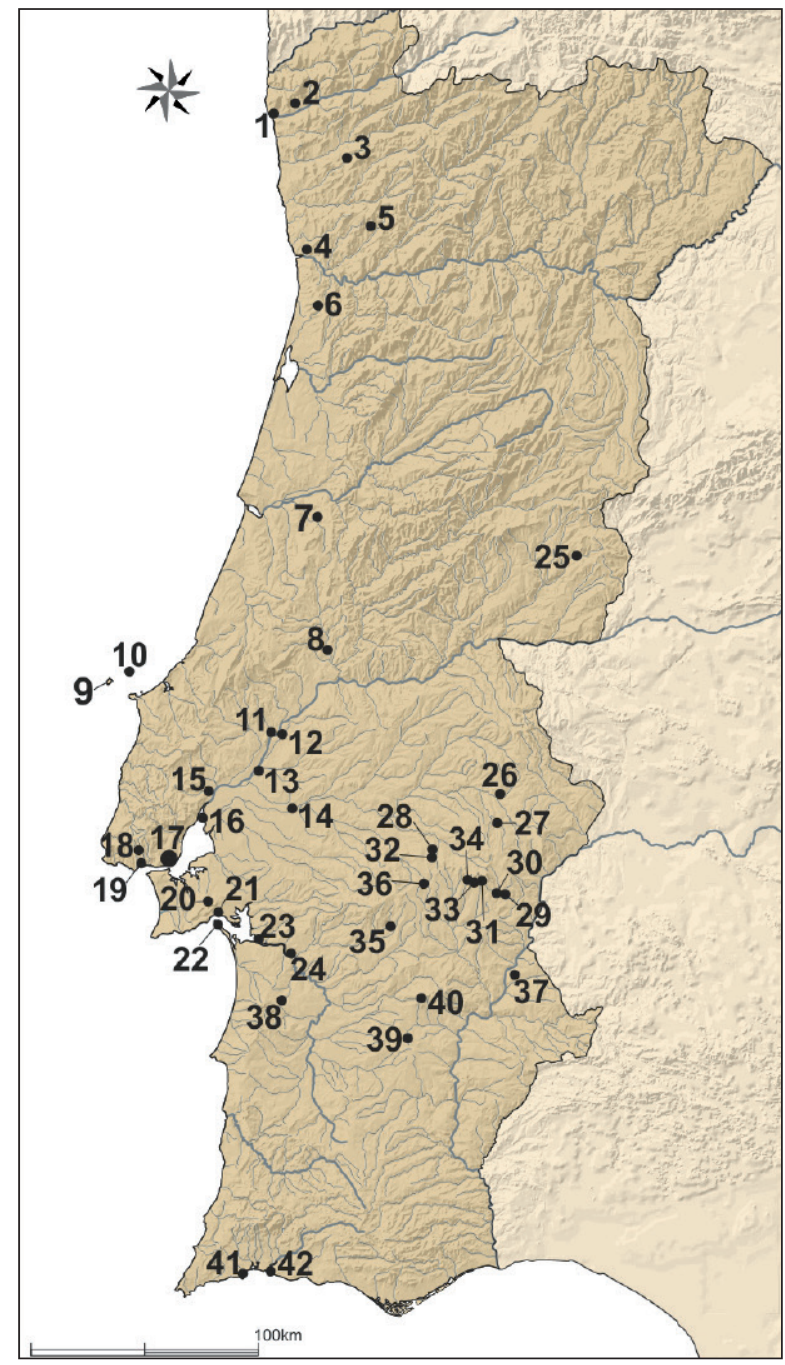

Figura 4. Difusión de las Lusitanas Antiguas en el território portugués: 1- Castro de Santa Luzia; 2- Castro da Terronha; 3-Braga; 4- Porto; 5- Lousada; 6- Castro de Fiães; 7Conimbriga; 8- Tomar; 9- Berlengas; 10- Ao largo das Berlengas; 11- Santarém; 12- Alto dos Cacos; 13- Muge; 14- Coruche; 15- Monte dos Castelinhos; 16- Rio Tejo; 17- Lisboa; 18- Alto das Cabeças (Oeiras); 19- Freiria; 20Chibanes; 21- Setúbal; 22- Tróia; 23- Abul; 24- Alcácer do Sal; 25- Idanha-a-Velha; 26- região de Monforte; 27-Castelo Velho de Veiros; 28- Soeiros; 29- S. Miguel da Mota; 30Rocha da Mina; 31- Caladinho; 32- Santa Justa; 33- Monte do Almo; 34- Vidigueira (Serra d'Ossa); 35- Tourega; 36Castelo dos Mouros; 37- Castelo da Lousa; 38- Cerrado do Castelo; 39- Monte da Cegonha; 40- S. Cucufate; 41- Monte Molião; 42- Foz do rio Arade.

la existencia de una Haltern 70 Lusitana en el Banco de Portugal (fig. 15, $\mathrm{n}^{\mathrm{o}} 78$ ), que conserva restos de revestimiento resinoso en su interior.

\subsection{Difusión}

Sobre la base de los datos actualmente disponibles, el mapa de distribución de estos primeros modelos anfóricos muestra una difusión que cubre gran parte del territorio portugués (fig. 4), costero e interior, estando presente en varios sitios de Galicia y de la región entre el Duero y el Miño (Soeiro 1984, Paiva 1993, Morais 2003), en Braga (Morais et al. 2016), Lousada (Sousa et al. 2006), Conímbriga (Buraca 2005: 47, Buraca 2016: 234-236), Tomar (Prudêncio et al. 2005: 206-207), Berlengas (Bugalhão y Lourenço 2006: 284289, Bugalhão y Lourenço 2011: 207-208), Alto das Cabeças, Oeiras (Cardoso 2011: fig. 91), Freiria (Cardoso 2015: 363), Lisboa (Filipe 2008a, Filipe 2008b, Dias et al. 2012, Almeida y Filipe 2013, Silva 2014, Filipe 2015, Silva 2015, Silva et al. 2016, Gomes et al. 2017), Monte dos Castelinhos (Pimenta y Mendes 2014: 131, Pimenta 2017: 202-203), Alto dos Cacos (Pimenta et al. 2012: 56, Pimenta et al. 2014: 270, Almeida y Pimenta 2018: 9), Santarém (Arruda et al. 2006a: 238-243), Coruche (Quaresma y Calais 2005: 439-440), Idanha-a-Velha (Banha 2006: 70), Mérida (Almeida y Sánchez Hidalgo 2013: 50, Almeida, 2016: 195-201), Tróia (Diogo y Trindade 1998: 196, Almeida et al. 2014a: 408, Almeida et al. 2014b: 657, Pinto et al. 2016: 177), Setúbal (Silva y Coelho-Soares 2014: 336), Chibanes (Trindade y Diogo, 1998: 173), Alcácer do Sal (Pimenta et al. 2006: 304-309, Pimenta et al. 2015: 158-160), S. Miguel da Mota, Alandroal (Guerra et al. 2003: 431), Castelo da Lousa (Morais 2010: 190191), región de Monforte (Boaventura y Banha 2006), Soeiros, Arraiolos (Calado et al. 1999: fig. 5, Mataloto y Angeja 2015: 853), Castelo dos Mouros, Évora (Mataloto 2008: 131), Castelo Velho de Veiros, Estremoz (Mataloto y Roque 2012: 675), Rocha da Mina, Alandroal (Mataloto y Roque 2013: 136, Mataloto et al. 2016: 146), Caladinho, Santa Justa, Monte do Almo y Vidigueira, todos en la región de la Serra d'Ossa (Mataloto 2010, Mataloto et al. 2014), Cerrado do Castelo, Grândola (Ferreira et al. 1991: 109), Tourega, Évora (Pinto y Lopes 2006: 215, fig. 15, no 13), Monte da Cegonha, Vidigueira (Pinto y Lopes 2006: 215, fig. 7), São Cucufate (Mayet y Schmitt 1997: 100), Monte Molião (Arruda y Viegas 2016: 446) y desembocadura del rio Arade (Fonseca 2015: 62-63).

Sin estar del todo claro, e incluso posiblemente atribuible en parte a la geografía de la investigación, su escasez en Algarve puede estar relacionada con la mayor dependencia de ese territorio respecto al área de influencia de Cádiz durante los primeros siglos de nuestra 


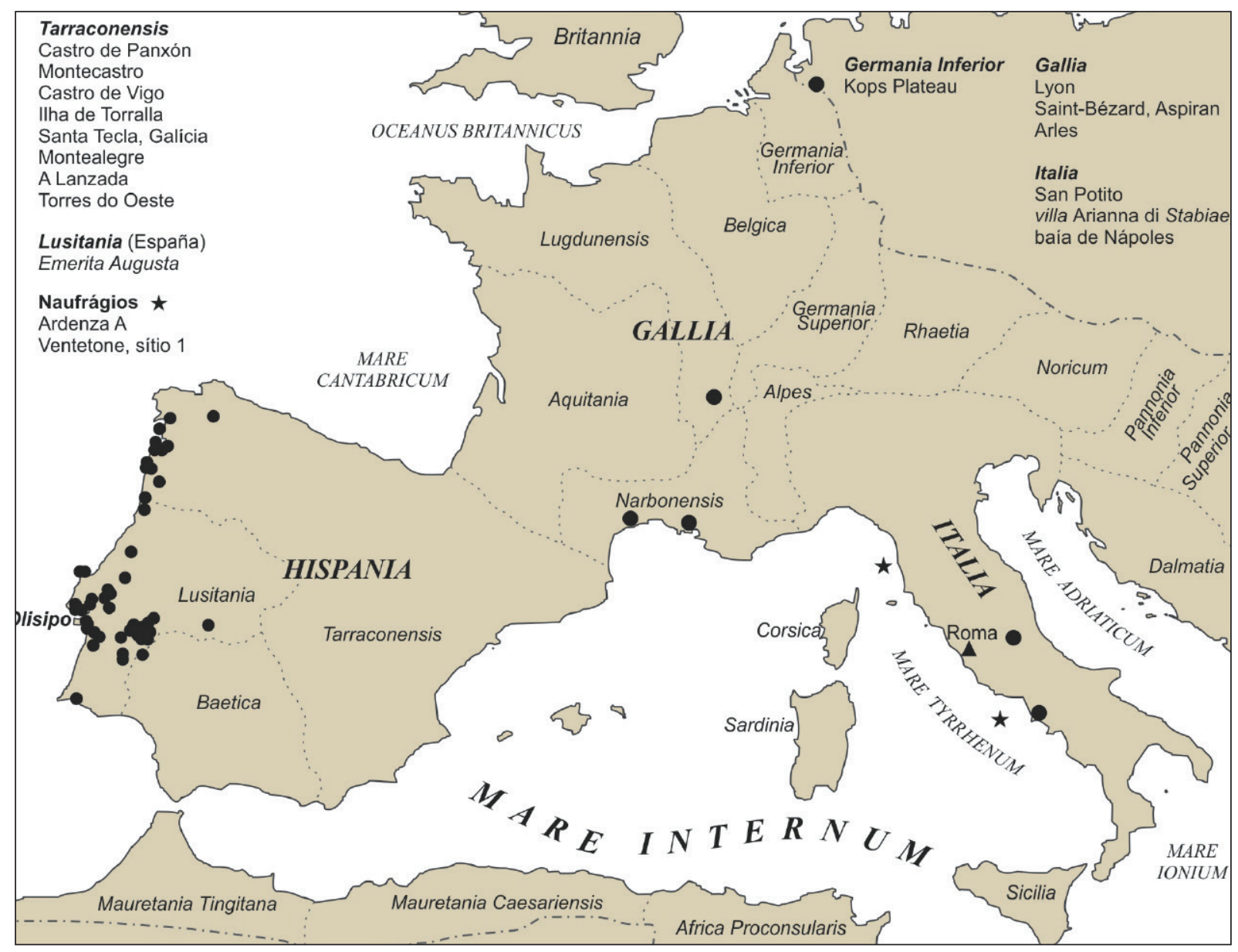

Figura 5. Difusión de las Lusitanas Antiguas en el Imperio Romano.

Era (Viegas 2011: 206), constituyendo muy probablemente la fabricación local de la Haltern 70 una producción minoritaria.

Si la amplia difusión de estas ánforas en toda la fachada atlántica de la península ibérica pudiera ya intuirse sobre la base de los datos publicados en los últimos años, incluso en la capital de la provincia $A u$ gusta Emerita, donde está bien atestiguada (Aquilué Abadias y Bello Rodrigo 2009: 434, Almeida y Sanchez Hidalgo 2013: 50, Almeida 2016: 211), su identificación en el Sur de Francia, en lugares como Lyon (Bertrand et al. 2014: Pl. 33), Saint-Bézard, Aspiran (Mauné y Duperron 2012: 135-136) y Arles (Djaoui y Quaresma 2016: 358-351), así como en Germania Inferior, en Kops Plateau, Nijmegen (Almeida et al. 2014c, Almeida y González Cesteros 2017: 87), da otra dimensión a estas producciones y a la fase inicial de exportación y distribución de los productos piscícolas lusitanos a puntos más alejados del Imperio (fig. 5). A estos lugares hay que añadir su posible presencia en San Potito, en el lado adriático de la península itálica (Hárshegyi 2007: fig. 10, n 127), y en la villa Arianna di Stabiae, en la bahía de Nápoles (Federico 2007: fig. 10, $\mathrm{n}^{\mathrm{o}}$ III, y fig. 16), así como en los naufragios Ardenza A y Ventotene, Sitio 1, cerca de la costa tirrénica de la península itálica (Bombico 2016: 241 y 262).

\section{LAS LUSITANAS ANTIGUAS EN OLISIPO: NUEVOS DATOS}

El estudio realizado recientemente sobre las ánforas romanas de Lisboa (Filipe 2019) destacó la importancia que tuvieron las primeras producciones anfóricas plenamente romanas del extremo occidental de Hispania en la dinámica comercial de la ciudad y en la economía de la región. Estos contenedores son uno de los tipos mejor representados en el conjunto global de las 
ánforas del Alto Imperio de Lisboa (aunque en realidad no corresponden a uno sino a varios tipos distintos), solo superados por las Dressel 14, las Lusitana 3 y las Dressel 20 del valle del Guadalquivir. Representan el $8,65 \%$ de la muestra total de ese período, lo que constituye una buena demostración de la vitalidad de la industria pesquera y alfarera lusitana durante la fase inicial de producción de esas ánforas.

Si consideramos solo las producciones anfóricas atribuibles al siglo I d.C. conocidas en Olisipo, las Lusitanas Antiguas son las formas mejor representadas en la ciudad, a las que solo se acercan, en términos de Número Mínimo de Individuos (NMI), las Dressel 20 de ese período. En Lisboa se conoce actualmente un NMI de 327 Lusitanas Antiguas, 41 de los cuales clasificables como Haltern 70 Lusitana, procedentes de toda la zona de la antigua ciudad (fig. 6), destacando su escasez en el área del Castillo de Lisboa y una mayor concentración en la zona de la actual Baixa Pombalina. Se trata del mayor conjunto conocido de este tipo de ánforas.

En esta importante ciudad en la desembocadura del Tajo, las Lusitanas Antiguas están documentados en los siguientes sitios: Teatro Romano (Filipe 2008a, Filipe 2015, Filipe 2019), Rua dos Bacalhoeiros (Filipe 2008b, Filipe 2019), en las antiguas (Almeida y Filipe 2013, Filipe 2019) y recientes intervenciones en la Praça da Figueira (Silva et al. 2016, Filipe 2019), Rua dos Remédios (Silva 2015, Filipe 2019), FRESS (Silva 2014), Casa dos Bicos (Filipe et al. 2016, Filipe 2019), NARQ (Dias et al. 2012), en las antiguas (Filipe 2019) y recientes excavaciones en la Rua das Pedras Negras (Gomes et al. 2017, Filipe 2019), Encosta de Sant'Ana, Circo Romano, Rua Augusta (1988), Rua do Ouro (n 133-145), Zara/ Rua Augusta, Criptopórtico de la Rua da Prata, Banco de Portugal, Escadinhas de S. Crispim, Palácio dos Condes de Penafiel, Calçada do Correio Velho, Largo de Santo António, Claustros de la Catedral, Beco do Marquês de Angeja, en las intervenciones de 2001 y de 2009 de la Rua de S. João da Praça, Palácio do Marquês de Angeja, Pátio José Pedreira y en la Rua do Espírito Santo (Filipe 2019).

Desafortunadamente, los datos estratigráficos son escasos para la fase de producción anterior al cambio de Era, que comprende solo un conjunto de fragmentos de pared de producción lusitana exhumados en un contexto que debería datarse en el tercer cuarto de siglo I a.C. en Beco do Marquês de Angeja (Filipe 2019), insuficiente para clasificar los tipos presentes, pero suficientemente representativos para confirmar su circulación en Olisipo en una fase anterior al Principado de Augusto. Además, se recogió un borde en la intervención del Pátio José Pedreira (fig. 14), en el Castillo de Lisboa, exhumado en un nivel de cronología poco clara, pero que, con probabilidad, podría datar de la segunda mitad del siglo I a.C. (Filipe 2019). Esta insuficiencia de datos estratigráficos en Lisboa para la fase más antigua de producción de estos contenedores es coherente con la escasez de materiales que se enmarcan típicamente en las imitaciones de Ovoide 1/Clase 67 que existen en la ciudad, presentes en el Palacio dos Condes de Penafiel (fig. 10). En la Catedral de Lisboa (fig. 11), los contextos más antiguos en los que se identificaron ánforas de este tipo datan del Principado de Augusto $\left(\mathrm{n}^{\circ}\right.$ 12598), de entre Augusto y el comienzo de Tiberio $\left(\mathrm{n}^{\mathrm{o}} 16206,12622,12644,16308,16310\right.$ y 16311), y del final del reinado de Tiberio al de Nerón $\left(\mathrm{n}^{\mathrm{o}} 11434\right.$, 13233, 13236, 13242, 13243, 13245, 13251, 16175, 16287 e 16288) (Filipe 2019).

Para la primera mitad del siglo I d.C. el volumen de información es mayor, pero aún así es demasiado reducido para la cantidad de materiales conocidos. El conjunto más numeroso de estos contenedores recogidos en contextos de la época proviene de la Praça da Figueira (Silva et al. 2016, Filipe 2019). El más antiguo corresponde una fosa [8933] (fig. 7), del comienzo de Tiberio, del que proceden un borde ( $\left.\mathrm{n}^{\circ} 30030\right)$, dos fondos ( $\mathrm{n}^{\mathrm{o}} 30030.09$ y 30030.10$)$ y cuatro asas. En el hoyo [8060] (fig. 7), de 20-40 d.C., se exhumaron cuatro bordes (9304.01, 30046.01, 2029.01 y 30032.01), dos fondos (30032.01 y 30032.03) y siete asas. Dos bordes ( $\mathrm{n}^{\mathrm{o}} 6433.01$ y 9665.02), un fondo (6433.03) $\mathrm{y}$ seis asas $(6418.01,6418.02,9665.01,6433.02 \mathrm{y}$ $6357.01)$ proceden de depósitos relacionados con la construcción del primer tablero de la vía, enmarcado entre el final del Principado de Tiberio y Claudio (fig. 7). Otro fondo (6628.01) del sector sur de la vía pertenece a un contexto con cronología entre Tiberio y Claudio (fig. 9). Atribuible al reinado de Claudio es un nivel de preparación de la vía secundaria donde se han identificado tres fragmentos de asa. En el sector norte de la vía, en los niveles de preparación para su construcción que datan de entre Claudio y Nerón, se recogieron cuatro bordes (30044.05, 30031.01, 30031.02 y 9837.01), un fondo (6316.02) y ocho asas (fig. 8). Por último, desde la fosa [9033], datada entre los años 60-70 d.C., se han exhumado siete asas y un borde (6731.32) (fig. 8).

En el Teatro Romano de Lisboa, solo se identificó un fragmento de asa en los niveles de la Fase I (final del principado de Augusto y comienzo de Tiberio), y 


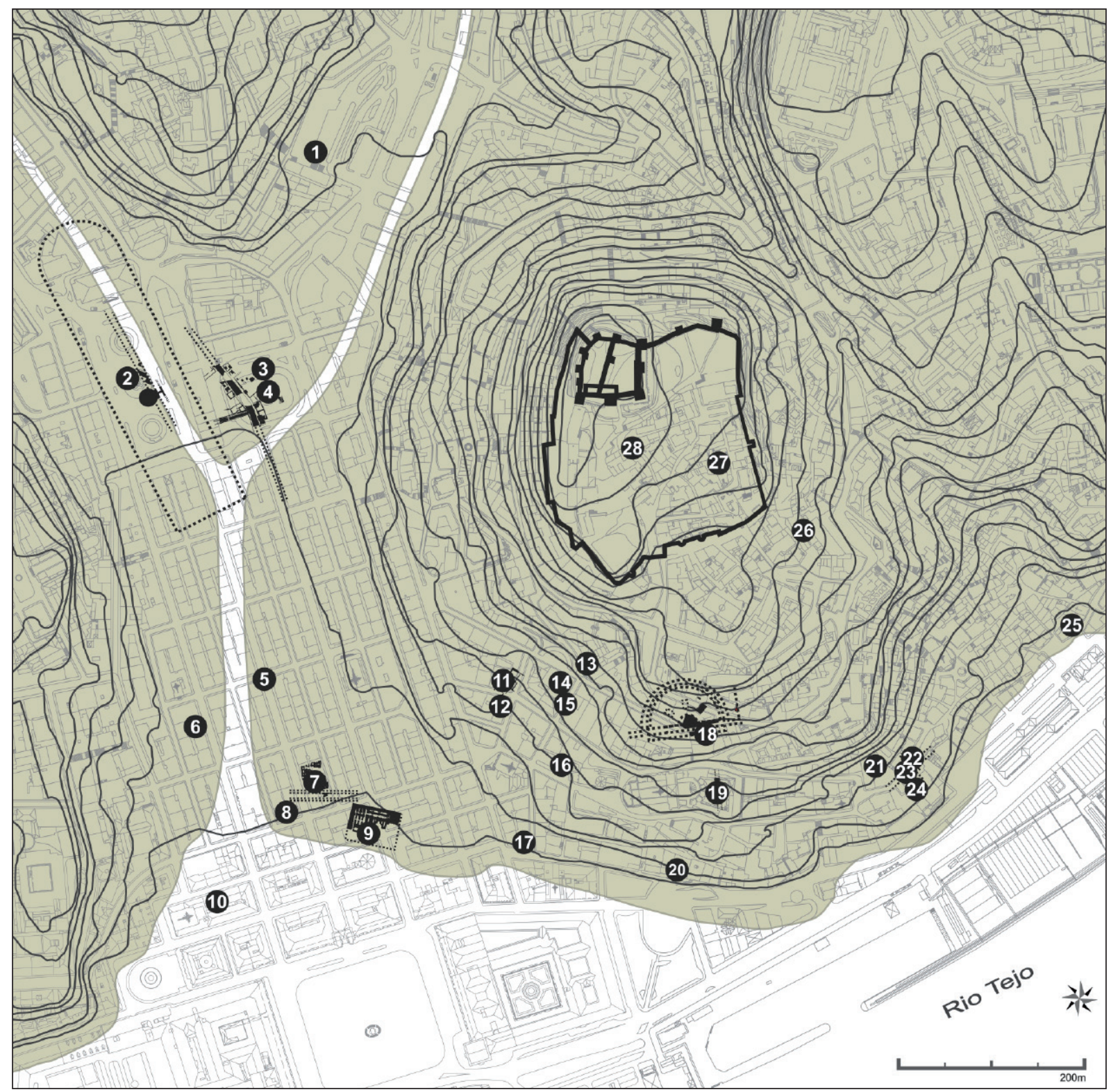

Figura 6. Procedencia de las Lusitanas Antiguas en la ciudad de Lisboa: 1- Encosta de Sant'Ana* (NMI 5); 2- Circo Romano* (NMI 2); 3- Praça da Figueira, 1961-1962 (NMI 4) (Almeida y Filipe 2013); 4- Praça da Figueira, 2000* (NMI 49); 5- Rua Augusta, 1988* (NMI 1); 6- Rua do Ouro, no 133-145* (NMI 1); 7- NARQ (Dias el al. 2012); 8- Zara, Rua Augusta* (NMI 57); 9- Criptopórtico* (NMI 7); 10- Banco de Portugal* (NMI 9); 11- Termas dos Cássios, 1991* (NMI 11); 12- Termas dos Cássios, 2013 (NMI 3) (Gomes et al. 2017); 13- Escadinhas de S. Crispim* (NMI 2); 14- Palácio dos Condes de Penafiel* (NMI 26); 15- Calçada do Correio Velho* (NMI 1); 16- Largo de Santo António* (NMI 4); 17- Rua dos Bacalhoeiros* (NMI 12) (Filipe, 2008b); 18- Teatro Romano de Lisboa* (NMI 48) (Filipe 2008a; Filipe 2015); 19- Claustros de la Catedral* (NMI 16); 20- Casa dos Bicos* (NMI 4); 21 - Beco do Marquês de Angeja* (NMI 1); 22- Rua de S. João da Praça, 2009* (NMI 1); 23- Rua de S. João da Praça, 2001* (NMI 5); 24- Palácio do Marquês de Angeja* (NMI 1); 25- Rua dos Remédios* (NMI 10), (Silva 2015; Silva et al. 2016); 26- Fundação Ricardo Espírito Santo e Silva (Silva, 2014); 27- Pátio José Pedreira* (NMI 1); 28- Rua do Espírito Santo* (NMI 1). *Filipe, 2019. 


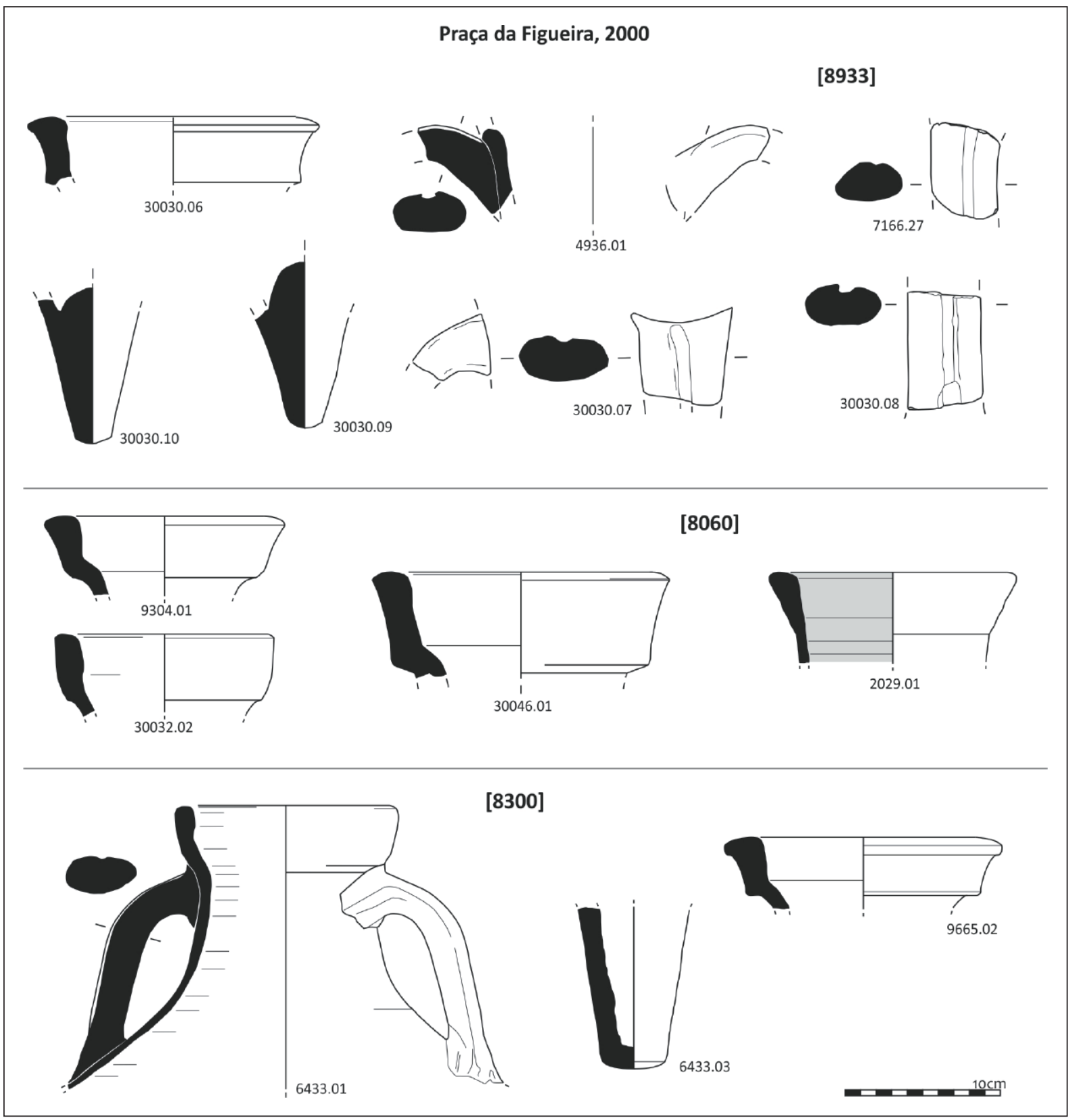

Figura 7. Lusitanas Antiguas de la Praça da Figueira. Todos los dibujos del contexto [8933] y los números 30032.02, 30046.01 y 6433.01 son adaptados de Silva et al. 2016 y Silva e.p.

tres bordes y un fondo (2649 y 5243, 2005; 1412, 2006; 7,2013 ; 2793, 2010) en los contextos de la Fase II, enmarcados cronológicamente alrededor de mediados del siglo I d.C. (Filipe 2015: 137-138). También de mediados del siglo I son los estratos de donde proceden la mayoría de los materiales de este tipo de la Rua dos Bacalhoeiros (Filipe 2008b), así como de la Rua dos Remédios, en este caso dos bordes y un asa (fig. 12)
(Filipe 2019). Por último, en la tienda de Zara, en Rua Augusta (Filipe 2019), donde se documentó el mayor conjunto de estas ánforas, se encuentran en cantidades significativas en contextos atribuibles a la segunda mitad del siglo I d.C. (fig. 13).

Los datos de este voluminoso conjunto de Lusitanas Antiguas de Lisboa no añaden información demasiado pertinente sobre la cronología del inicio de su 


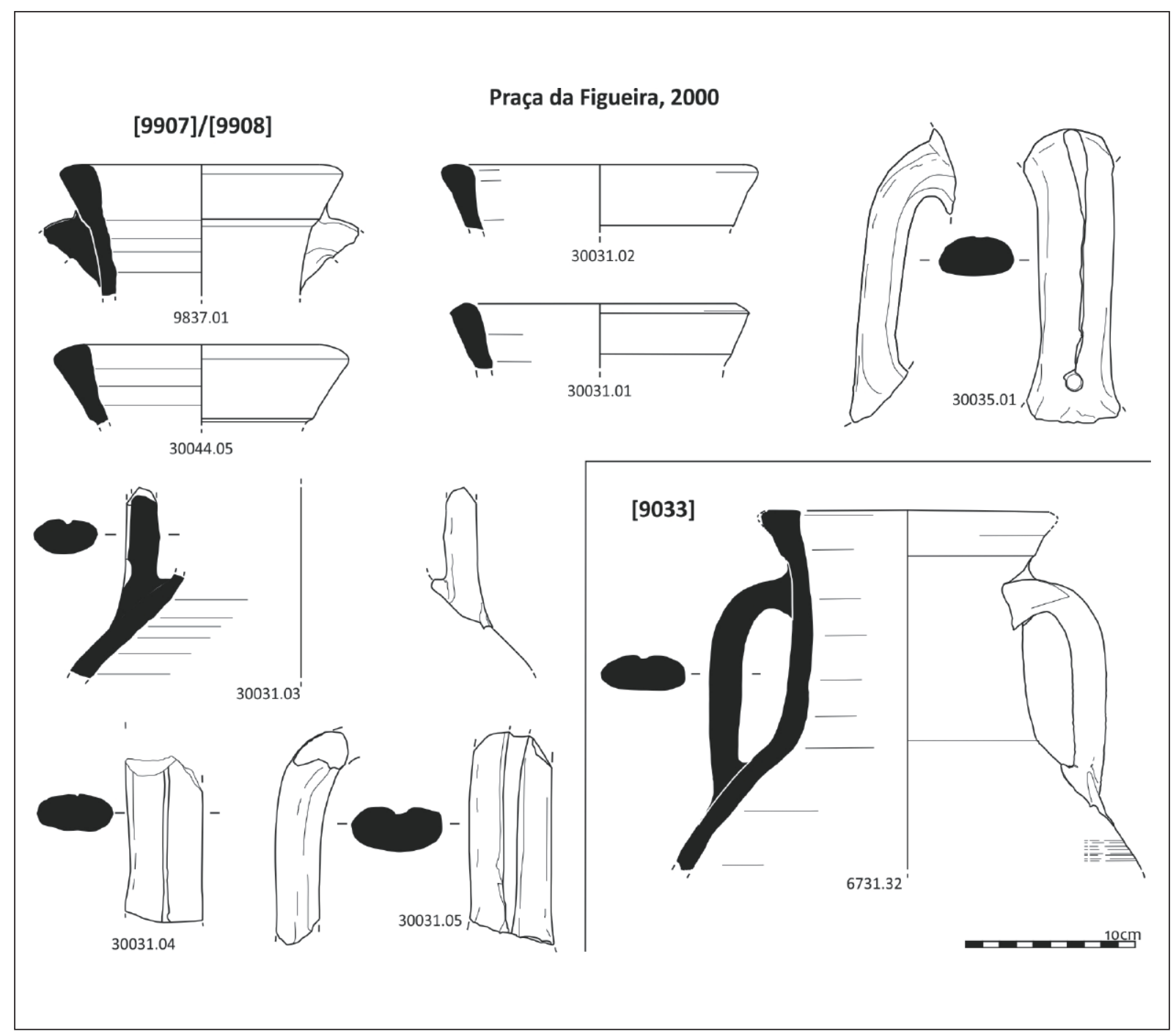

Figura 8. Lusitanas Antiguas de la Praça da Figueira. Los dibujos 6433.01, 30031.02, 30031.01, 30035.01, 30031.05, 30031.03, 6731.32 son adaptados de Silva et al. 2016.

producción, pero sí proporcionan buenas indicaciones para su fase final, en particular los de Praça da Figueira (Silva et al. 2016, Filipe 2019) y los de Zara, Rua Augusta (Filipe 2019). Las realidades registradas en el primer sitio documentan la comercialización de estas ánforas hasta el reinado de Nerón, destacando la ausencia de Dressel 14 en los mismos contextos (Silva et al. 2016).

De igual modo, la proporción de Lusitanas Antiguas en relación con la Dressel 14 en los niveles flavios de Zara, Rua Augusta, representada en su mayor parte por piezas atribuibles a la Lusitana 12, parece ser significativa. Por otra parte, en la Rua de São Mamede, en contextos cronológicamente enmarcados entre el último cuarto del siglo I d.C. y el primer tercio del siglo II (Mota et al. 2017), no se registra la presencia de las Lusitanas Antiguas, mientras que la Dressel 14 está muy bien representada.

Sobre la base de estos datos, puede afirmarse que la fase final de producción de las ánforas con morfologías en el marco de las llamadas Lusitanas Antiguas se debería ubicar en el tercer cuarto del siglo I d.C., y debería haber tenido lugar al menos hasta el reinado de Vespasiano, en el caso de las formas atribuibles a Lusitana 12, que todavía habrán circulado con las primeras Dressel 14. 


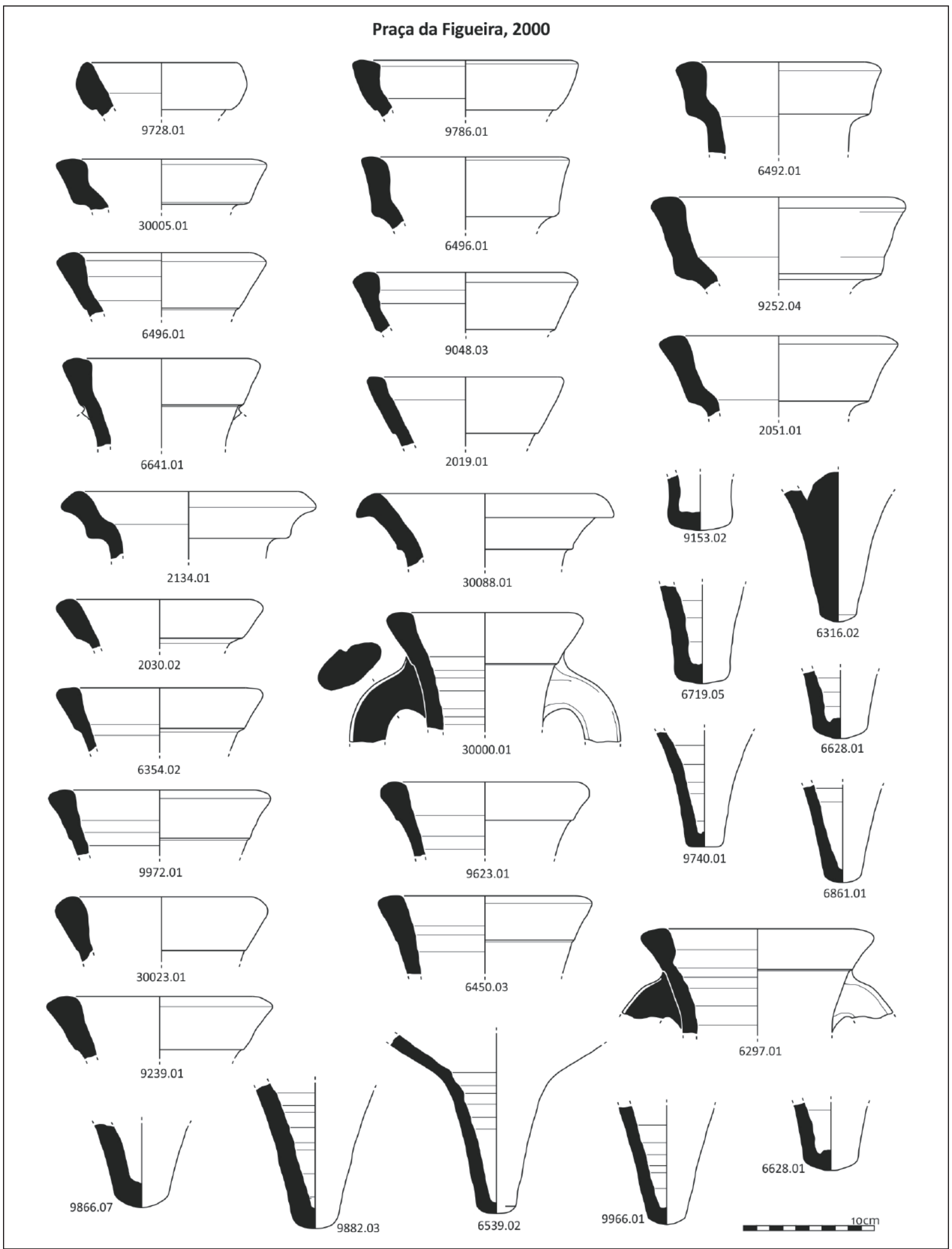

Figura 9. Lusitanas Antiguas de la Praça da Figueira. 


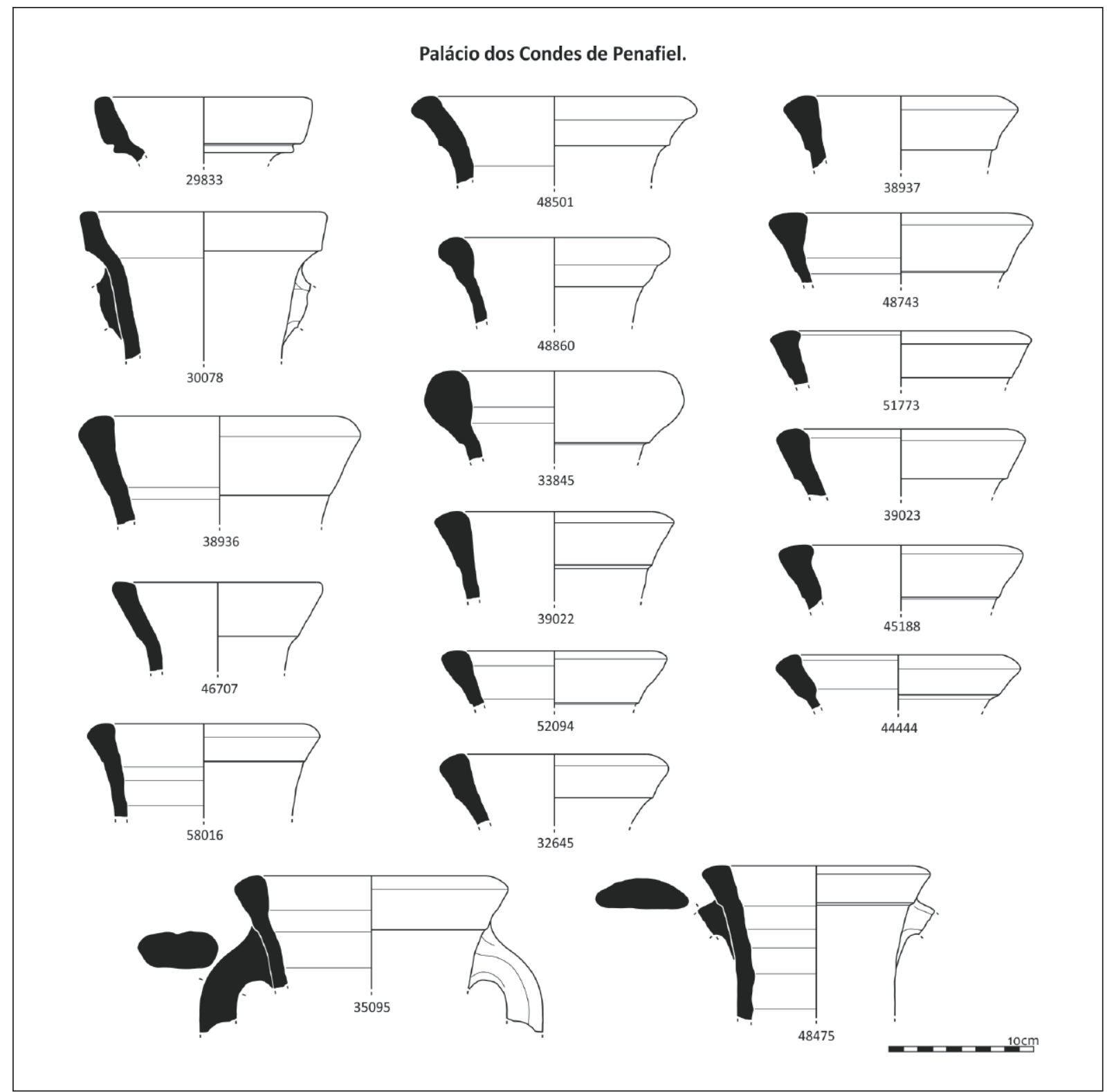

Figura 10. Lusitanas Antiguas del Palácio dos Condes de Penafiel.

En cuanto a las variantes observadas en la muestra de Olisipo, compuestas en su mayoría por formas que encajan en el universo de las Dressel 7-11, Haltern 70 y Lusitana 12, parece significativa la escasez de bordes relacionados con la Ovoide $1 /$ Clase 67 , relativamente bien representados en el Monte dos Castelinhos (Pimenta 2015, Pimenta 2017), en el interior de Alentejo (Morais 2010, Mataloto et al. 2016) y en su Noroeste (Morais 2003, Morais y Fabião 2007). Igualmente escasos en Lisboa son los bordes de perfil subtriangular o subrectangular, observables en contextos republicanos tardíos en Pedrão (Mayet y Silva 2016: 63, fig. 6, $\left.\mathrm{n}^{\mathrm{o}} 1-3\right)$ y en el interior del Alentejo (Morais 2010, Mataloto et al. 2016).

Del mismo modo, tanto en Lisboa como al parecer en el resto del territorio portugués, hay pocas variaciones del borde redondeado y engrosado en el exterior y liso en el interior, de las cuales solo se conocen dos ejemplares en Olisipo, en la Praça da Figueira (fig. 9, no 9728.01) y en la Catedral (fig. 11, n 11010) 


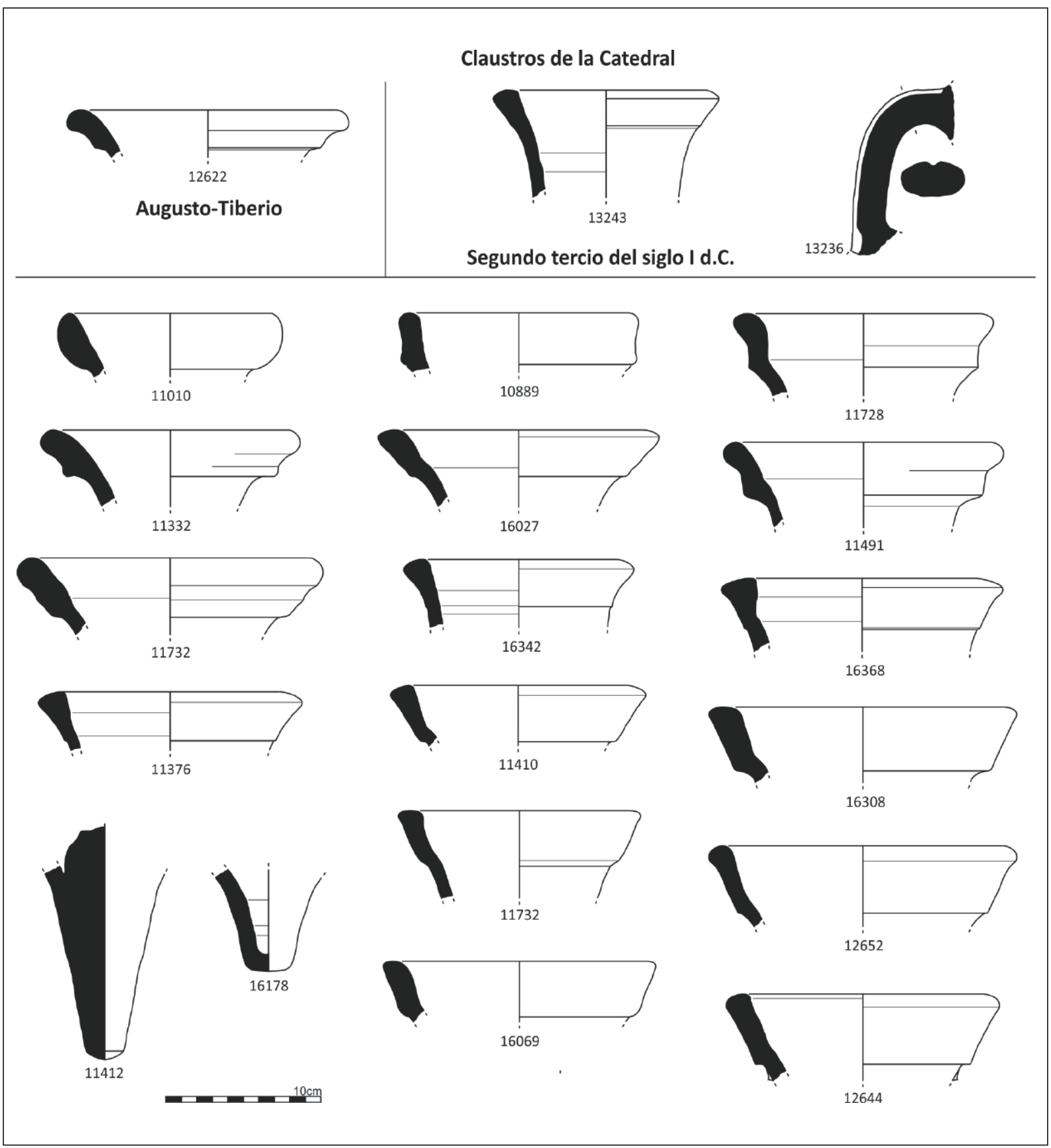

Figura 11. Lusitanas Antiguas de los Claustros de la Catedral.

(Filipe 2019), cuyo mejor paralelo parece ser una pieza del Monte dos Castelinhos (Pimenta 2017: 201, fig. $6, \mathrm{n}^{\mathrm{0}} 5$ ). Esta variante tiene notables similitudes con el tipo VC de Apani (Palazzo 2013: 22) y, en menor medida, con la Ovoide 6 del valle del Guadalquivir (García Vargas et al. 2011), del que se diferencia principalmente por la apertura del cuello y el borde. Son dignas de mención las diversas variantes que se pueden encuadrar en las Dressel 7-11 y Haltern 70, lo que plantea la cuestión, ya mencionada, de un hipotético bajo nivel de estandarización.

En relación con la posible importancia cronológica atribuible a las diferentes variantes de borde, los datos siguen siendo relativamente escasos. En el caso 


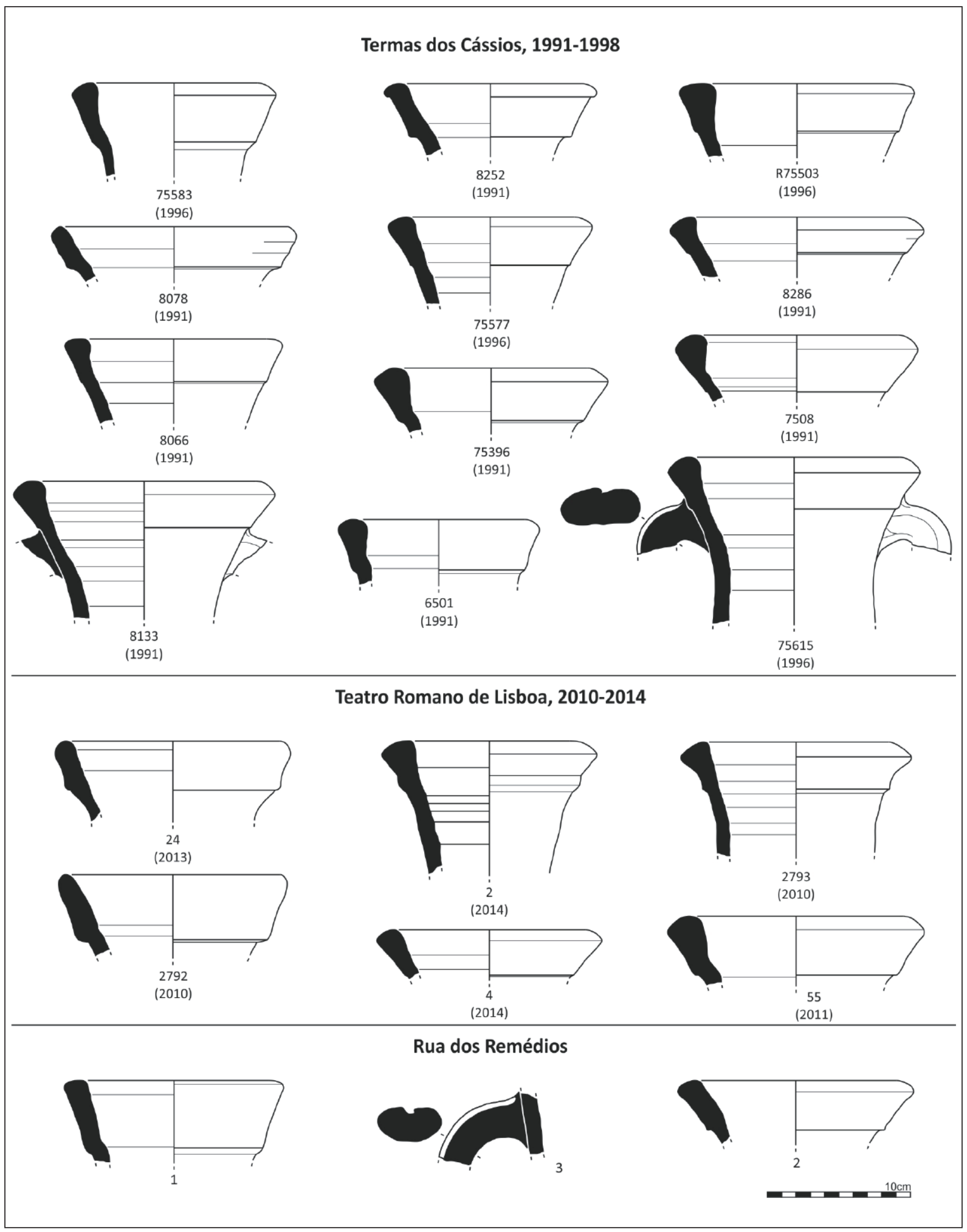

Figura 12. Lusitanas Antiguas de las Termas dos Cássios, del Teatro Romano de Lisboa y de la Rua dos Remédios. 
50 - 100 d.C.

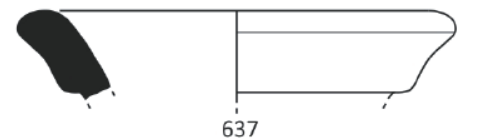

637

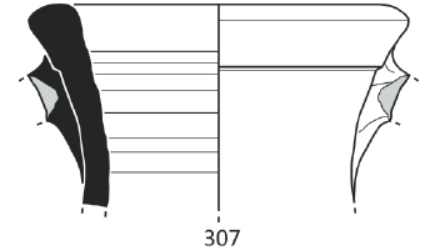

307

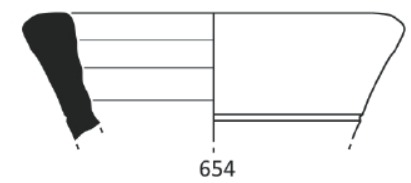

654

Flavios
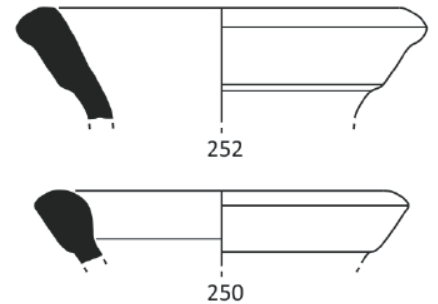

i

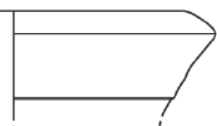

594

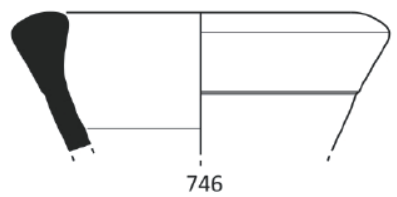

$10 \mathrm{~cm}$
Zara, Rua Augusta
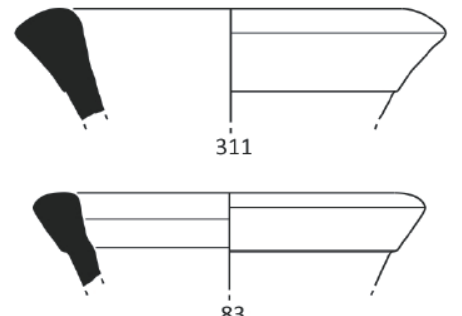

83

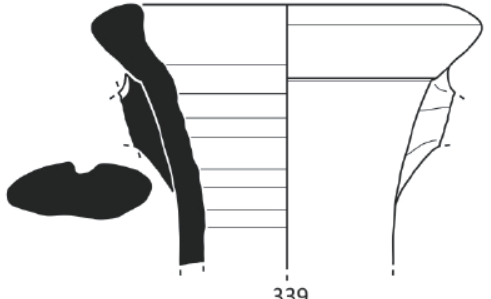

339
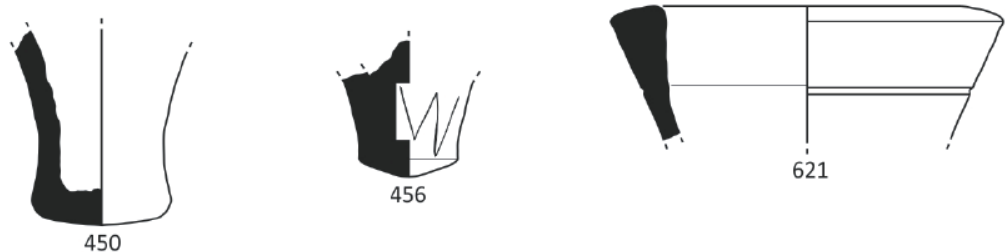

621

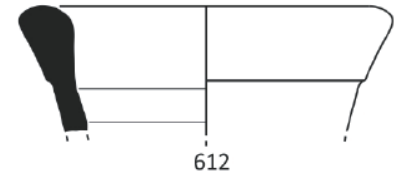

248

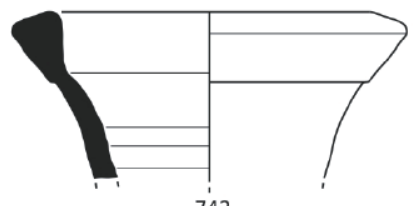

742

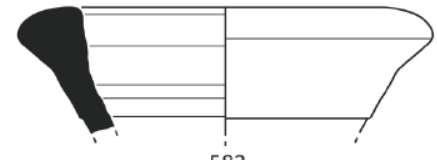

583

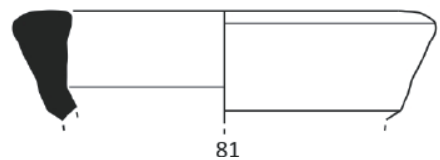

593

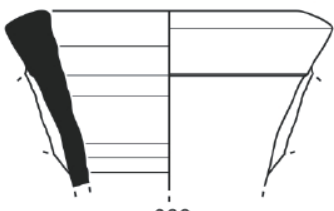

290

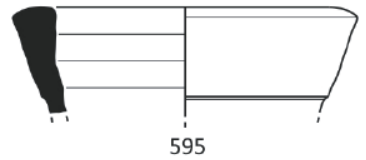

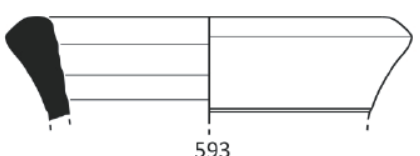

Figura 13. Lusitanas Antiguas de Zara (Rua Augusta).

concreto de Lisboa, donde las Lusitanas Antiguas están bien documentadas en contextos de los tres primeros cuartos del siglo I d.C., la escasez de los tipos antes mencionados (relacionados con la Ovoide 1/Clase 67 y los bordes de perfil subtriangular o sub-rectangular) parece ser significativa, y se puede observar ahí una indicación de que su producción cesó alrededor del cambio de Era o incluso un poco antes, como ya se ha sugerido (Almeida y Fabião 2019, Filipe 2019). Aunque esta conclusión parece estar de acuerdo con la cronología de los sitios donde se atestiguan estas variantes, por supuesto, necesitará confirmación en el futuro. 


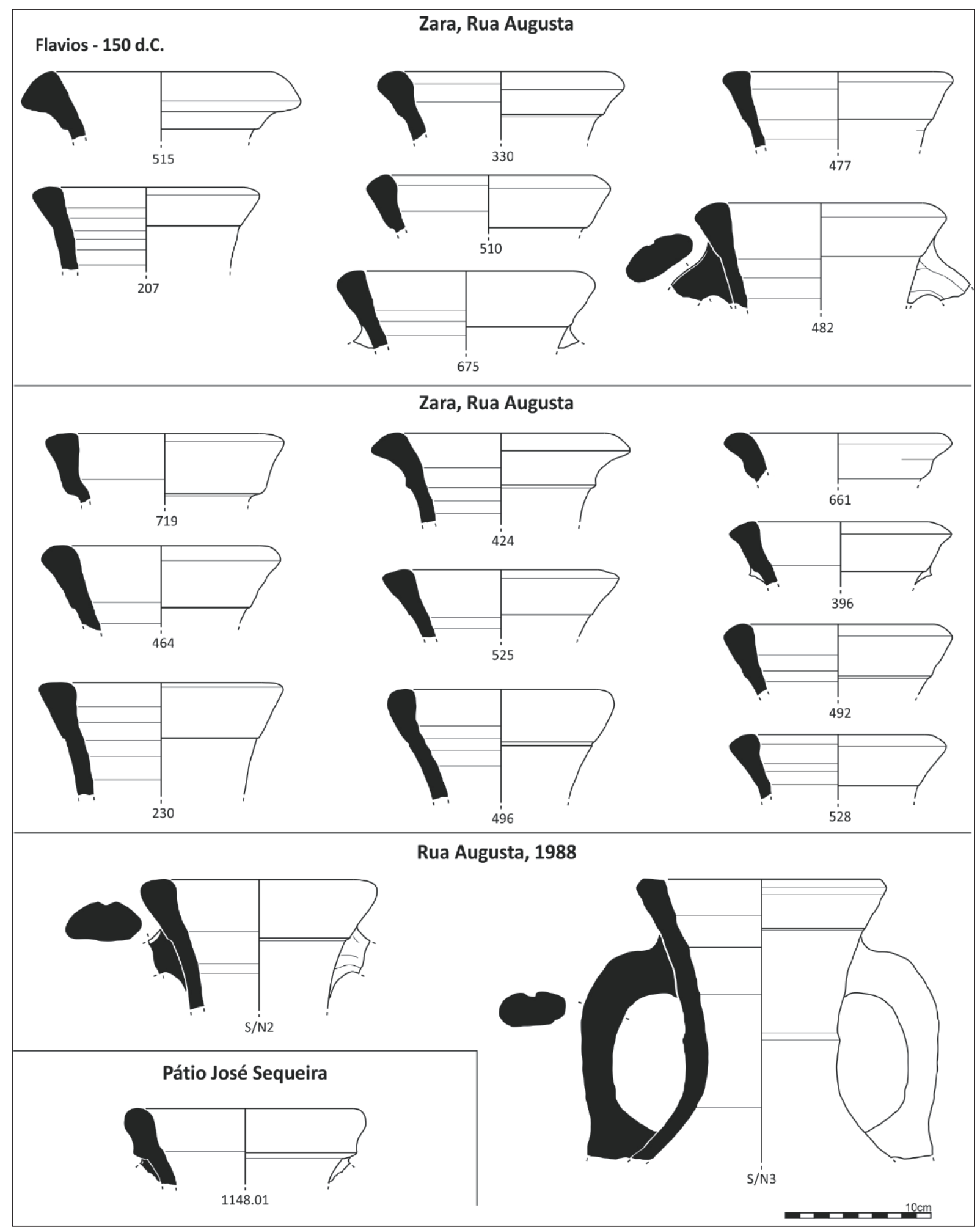

Figura 14. Lusitanas Antiguas de Zara (Rua Augusta), de Rua Augusta (1988) (S/N3: trabajado sobre original de Carlos Fabião) y del Pátio José Pedreira. 

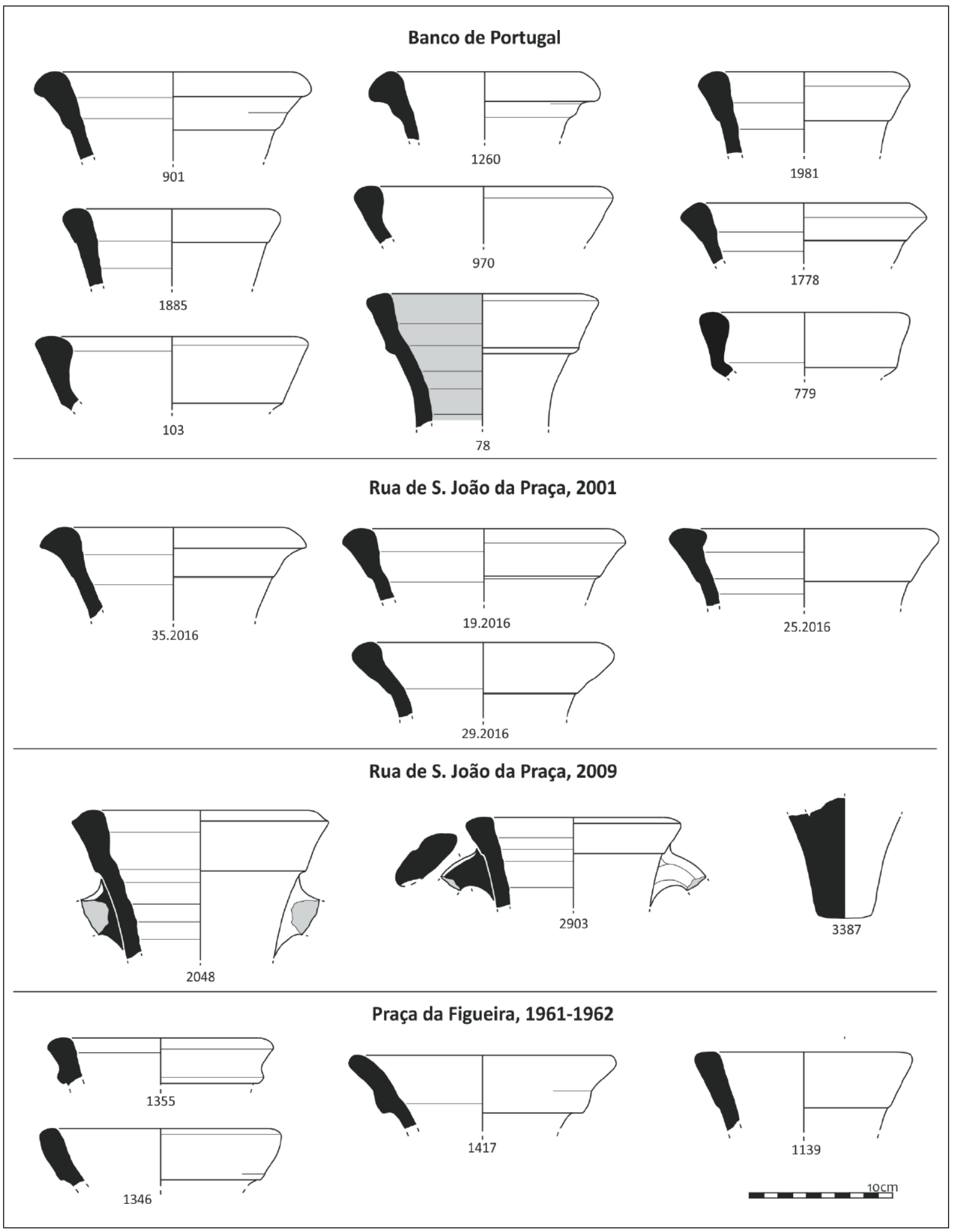

Figura 15. Lusitanas Antiguas del Banco de Portugal, de la Rua de S. João da Praça (2001 y 2009) y de la Praça da Figueira, 1961-1962 (diseños 1355 y 1346, in Almeida y Filipe 2013). 


\section{CONCLUSIONES}

A partir del segundo cuarto del siglo I a.C., pero especialmente desde mediados de ese siglo, se asiste a lo que Carlos Fabião llamó «el progresivo ascenso económico de la Península Ibérica» (Fabião 1989: 121, Fabião 1998: 182), demostrado por el importante aumento de las importaciones del área sur de la Ulterior. Se caracteriza fundamentalmente por la hegemonía de los productos de esa región, en particular el vino y el aceite del valle del Guadalquivir y los preparados de pescado de la zona costera, así como por la fuerte disminución de la importación del vino itálico. El nuevo o remodelado repertorio anfórico ha estado dominado desde entonces por las formas ovoides del valle del Guadalquivir y de la costa sur de la Ulterior, mientras que las T-7.4.3.3., junto con las Dressel 1 itálicas, parecen haber disminuido significativamente desde entonces.

Estos cambios profundos en relación con el período inmediatamente anterior son generalmente transversales a todo el occidente de la Península y al resto de la Hispania (Mateo Corredor 2014), encajando con las importantes transformaciones comerciales que se produjeron en gran parte del Imperio durante la segunda mitad del siglo I a.C. y sobre todo durante el principado de Augusto. Se observa una inversión de la tendencia en las relaciones centro-periferia, en las que Italia ya no es la principal región productora y exportadora, sino la principal beneficiaria (especialmente Roma) de los productos de las provincias, a las que llegan las mercancias itálicas en cantidades cada vez menores (Tchernia 1986: 157-158, Fabião 1998: 178, Mateo Corredor 2014: 681). En el actual espacio portugués, este aumento de los productos béticos en paralelo con la caída de las importaciones itálicas es reconocible en prácticamente todos los lugares que tuvieron ocupación durante la segunda mitad del siglo I a.C. Se puede destacar la Lomba do Canho (Fabião 1989), Alto dos Cacos (Pimenta et al. 2012, Pimenta et al. 2014, Almeida y Pimenta 2018), en Santarém (Arruda y Almeida 1999, Arruda y Almeida 2001), en el Castelo da Lousa (Morais 2010), en Mesas do Castelinho (Parreira 2009), en Monte Manuel Galo (Alves 2014) y en Monte Molião (Arruda y Sousa 2012), siendo especialmente evidente en Monte dos Castelinhos (Pimenta y Mendes 2014, Pimenta 2015, Pimenta 2017) y en Castro Marim (Arruda et al. 2006b, Viegas 2011), donde las producciones itálicas presentan proporciones particularmente bajas.

Es en este contexto, durante el tercer cuarto del siglo I a.C., en el que aparecen las primeras producciones anfóricas plenamente romanas del extremo occidental de la Península que, aunque muy escasas en Olisipo (véase más arriba), están bien documentadas en contextos que datan de ese período en el valle del Tajo, en Monte dos Castelinhos (Pimenta y Mendes 2014, Pimenta 2015, Pimenta 2017) y en el Alto dos Cacos (Pimenta et al. 2012, Pimenta et al. 2014, Almeida y Pimenta 2018), en el valle del Sado (Mayet y Silva 2016: 64) y en el interior del Alentejo, en Rocha da Mina (Mataloto y Roque 2013, Mataloto et al. 2016).

En esta fase más antigua, la aparición de estos contenedores parece coincidir, al menos en parte, con los sitios con una presencia militar comprobada o con parte en el proceso de romanización y articulación del interior del territorio que, al mismo tiempo, coinciden con los circuitos de distribución de las ánforas surpeninsulares de la segunda mitad del siglo I a.C. (García Vargas et al. 2011: 265, Almeida y Fabião 2019: 180). Esta estrecha relación con los contingentes militares y los principales agentes de la romanización parece ser especialmente evidente en la fase inmediatamente posterior, constituida por el principado de Augusto, en la que, además de la continuidad de su ocurrencia en las mencionadas regiones del valle del Tajo, el valle del Sado y el Nordeste del Alentejo, ahora en proporciones más significativas, existe una importante concentración en el Noroeste de la Península (Morais 2003, Morais y Fabião 2007, Carreras Monfort y Morais 2010, Carreras Monfort y Morais 2011, Fernández Fernández 2013).

Esta importante concentración de las primeras producciones anfóricas de Lusitania en una zona en la que se desarrollaban las llamadas Guerras Cantábricas, de alguna manera puede estar relacionada con la presencia de militares en la región, lo que podrá haber sido uno de los principales impulsos para el energético desarrollo que se produjo en la producción de envases anfóri$\cos \mathrm{y}$, por consiguiente, de preparados de pescado en el extremo occidental de la Península durante este período, adquiriendo a partir de ese momento una escala bastante significativa. Es precisamente durante el principado de Augusto cuando la producción local/regional de ánforas de pescado parece despegar con mayor energía, introduciendo algunos cambios en el perfil de las importaciones, lo que da lugar a una disminución gradual de la afluencia de este tipo de alimentos procedentes del área gaditana, aunque siempre en porcentajes significativos. Aún así, no está del todo claro si las Lusitanas Antiguas superan en número a las importaciones de la costa bética en este momento o solo durante el principado de Tiberio.

De hecho, en los pocos contextos documentados en Olisipo de la época de Augusto, los datos parecen ser 
contradictorios. Mientras que en los claustros de la $\mathrm{Ca}$ tedral, en los niveles de esta fase, hay una expresiva superioridad de los productos de la Bética sobre los de la Lusitania, evidenciada en la presencia de las Dressel 7-11 y Dressel 12 de la primera región (además de T-7.4.3.3. que debería corresponder principalmente a producciones residuales) y de las Lusitanas Antiguas de la segunda (Filipe 2019), en el Teatro Romano hay una situación muy diferente. En los contextos de la Fase 1 de este último sitio - datados en los últimos años del reinado de Augusto/principios de Tiberio (Filipe 2008a, Filipe 2015) - están presentes las Lusitanas Antiguas, mientras que los artículos de pescado béticos solo están atestiguados por las T-7.4.3.3., que deberían corresponder en gran parte, si no totalmente, a materiales residuales. Todavía en la Catedral, en contextos algo posteriores pero no más allá del final del primer tercio del siglo I d.C., se observa un cierto equilibrio entre el consumo de productos béticos y lusitanos a base de pescado, aunque con una ligera ventaja para los últimos (Filipe 2019).

En la Praça da Figueira, en los hoyos [8933] y [8060], que datan respectivamente del período inicial del Tiberio y de los años 20-30 d.C., además de una importante presencia de las Lusitanas Antiguas, las ánforas piscícolas béticas están totalmente ausentes, aunque se atestiguan en casi todos los demás contextos de este sitio (siempre en proporciones inferiores a las de las Lusitanas Antiguas) datados entre el final del principado de Tiberio y el de Nerón (Silva et al. 2016, Filipe 2019). Una situación similar se puede observar en los niveles que datan del mismo período registrados en los claustros de la Catedral (Felipe 2019), en los contextos asociados a la remodelación del Teatro Romano de Lisboa a mediados del siglo I d.C. (Filipe 2008a, Filipe 2015), en la Rua dos Bacalhoeiros (Filipe 2008b) y en la Rua dos Remédios (Silva 2015, Filipe 2019). El cruce de estos datos contextuales con las estadísticas globales de Olisipo (Filipe 2019), donde las Lusitanas Antiguas son significativamente más expresivas que las producciones piscícolas béticas del mismo período, demuestra la clara supremacía de los artículos lusitanos sobre los béticos al menos desde el inicio del principado de Tiberio, posiblemente ya desde el final del de Augusto, confirmando lo que ya se había propuesto a partir de la muestra del Teatro Romano de Lisboa (Filipe 2015: 158).

El segundo cuarto del siglo I d.C. representa el período de mayor actividad comercial en Olisipo, que aparentemente se extiende al resto del Occidente hispano, alcanzando su apogeo durante el reinado de
Claudio y el comienzo del de Nerón, en torno a mediados de siglo. Para eso ha contribuido el desarrollo de la industria pesquera lusitana, cada vez más importante en el abastecimiento local y regional, junto con la importación de aceite de oliva y vino del valle del Guadalquivir en grandes cantidades, cuyo influjo tendrá que relacionarse también con la conquista de Bretaña emprendida por Claudio y el relevante y estratégico papel desempeñado por la ruta atlántica en estas campañas (Fabião 2009, Remesal 2010), manteniendo el fuerte crecimiento urbano de Olisipo que había comenzado con Augusto (Filipe 2019).

En el estado actual de la investigación, los datos contextuales de Olisipo, a pesar de su relativa escasez en términos proporcionales, permiten atribuir al período entre los reinados de Tiberio y Nerón el momento de mayor auge en la producción y comercialización de las designadas Lusitanas Antiguas. Es precisamente de contextos que se remontan a ese período de donde procede la gran mayoría de las ánforas tipológicamente atribuibles a las Lusitanas Antiguas identificadas en Olisipo, procedentes de los claustros de la Catedral, la Praça da Figueira, el Teatro Romano, la Rua dos Bacalhoeiros, la Rua dos Remédios y Zara, en Rua Augusta.

Los datos de Lisboa también son relevantes para determinar el momento final de la producción de las Lusitanas Antiguas. En la Praça da Figueira su presencia está bien documentada en los contextos que datan de Nerón, junto con la ausencia de Dressel 14 (Silva et al. 2016, Filipe 2019). En Zara, Rua Augusta, las Lusitanas Antiguas representan la mayoría de los hallazgos en relación con la Dressel 14, en los niveles flavios (Filipe 2019). En los contextos documentados en la Rua de São Mamede, fechados entre el último cuarto del siglo I d.C. y el primer tercio del siglo II (Mota et al. 2017, Filipe 2019), hay una buena representación de las Dressel 14 a la par de la ausencia de las Lusitanas Antiguas. Sobre la base de estos datos, puede decirse que la producción y comercialización de estas ánforas lusitanas parece haber llegado a su fin ya durante la dinastía Flavia, presumiblemente en su fase inicial, en un momento en que ya había comenzado la producción del recipiente que constituirá, al menos hasta finales del siglo siguiente, el gran representante de los preparados de pescado producidos en la provincia más occidental del Imperio Romano: la Dressel 14.

En términos generales, en el tercer cuarto del siglo I d.C., más probablemente a partir de los últimos años del reinado de Nerón, se produjo una tendencia a la baja de las importaciones extraprovinciales, en particular de vino, que registra una fuerte caída, acompañada de un 
aumento de los productos piscícolas locales/regionales, impulsado principalmente por el importante desarrollo de la industria pesquera lusitana desde mediados de siglo, de la que la mencionada Dressel 14 es uno de los principales testimonios.

\section{Agradecimientos}

Este trabajo es el resultado de la realización de un proyecto de doctorado en Arqueología en la Facultad de Letras de la Universidad de Lisboa, habiendo contado con una beca para un doctorado (ref.: SFRH/BD/7958/2011) de la Fundación para la Ciencia y la Tecnología (FCT). Se agradece a FCT por la concesión de esta beca, así como a mi tutor, el profesor Carlos Fabião, e a UNIARQ (Centro de Arqueología de la Universidad de Lisboa) por todo el apoyo desde el principio.

\section{BIBLIOGRAFIA}

Almeida, R. R. (2016): "On the way to Augusta Emerita. Historiographical Overview, old and new data on fish-product amphorae and commerce within the trade to the capital of Lusitania", en I. V. Pinto, R. R. Almeida y A. Martin (eds.), Lusitanian Amphorae: Production and Distribution. Roman and Late Antique Mediterranean Pottery 10: 195-218. Oxford, Archaeopress Series.

Almeida, R. R. y Fabião, C. (2019): “The "early production' of Roman amphorae en Ulterior / Lusitania. State of play of a universe (still) under construction", en E. Garcia Vargas, R. R. Almeida, H. González Cesteros y A. M. Sáez Romero (eds.), The ovoid Amphorae en the Central and Western Mediterranean. Between the last two centuries of the Republic and the early days of the Roman Empire. Roman and Late Antique Mediterranean Pottery 13: 175-190. Oxford, Archaeopress Series.

Almeida, R. y Filipe, V. (2013): "50 anos depois: as ânforas da Praça da Figueira", en Actas do I Congresso da Associação dos Arqueólogos Portugueses: 737-745. Lisboa, Associação dos Arqueólogos Portugueses.

Almeida, R. R. y González Cesteros, H. (2017): “Las ánforas lusitanas en los origenes del mundo romano septentrional", en C. Carreras Monfort y J. Van der Berg, (eds.), Amphorae from the Kops Plateau (Nijmegen): trade and supply to the lowerrhineland from the Augustan period to AD 69/70.
Archaeopress Roman Archaeology 20: 87-91. Oxford, Archaeopress Series.

Almeida, R. R. y Pimenta, J. (2018): “Ânforas do acampamento/sítio romano de Alto dos Cacos (Almeirim, Portugal)". Onoba 6: 3-56.

Almeida, R. R.; Pinto, I. V.; Magalhães, A. P. y Brum, P. (2014a): "Ânforas piscícolas de Tróia: contextos de consumo versus contextos de produção", en R. Morais, A. Fernandez Fernandez y M. J. Sousa (eds.), As produções cerâmicas de imitação na Hispânia. Monografias Ex Officina Hispana II: I, 405-423. Porto, Faculdade de Letras da Universidade do Porto.

Almeida, R. R.; Pinto, I. V.; Magalhães, A. P. y Brum, P. (2014b): "Wich amphorae carried the fish products from Tróia (Portugal)?”, en Rei Cretariae Romanae Favtorvm Acta 43: 653-661. Bona, RCRF.

Almeida, R.; Berg, J.; Berni Millet, P.; Schimmer, F. y Carreras Monfort, C. (2014c): "El comercio de ánforas hispanas en Kops Plateau (Nijmegen) desde época de Augusto a época Flavia", en R. Morais, A. Fernandez Fernandez y M. J. Sousa (eds.), As produções cerâmicas de imitação na Hispânia. Monografias Ex Officina Hispana II: Vol. I, 379-392. Porto, Faculdade de Letras da Universidade do Porto.

Almeida, R. R. y Sánchez Hidalgo, F. (2013): "Las ánforas del Cuartel de Hernán Cortés. Nuevos datos para el estudio de la importación y consumo en Augusta Emerita", en D. Bernal, L. C. Juan, M. Bustamante, J. J. Díaz y A. M. Sáez (eds.), Hornos, talleres y focos de producción alfarera en Hispania. Monografías Ex Officina Hispana I: Vol. II, 49-58. Cádiz, Universidad de Cádiz.

Alves, C. (2014): “Os castella do Baixo Alentejo. O caso do Monte Manuel Galo", en C. Fabião y J. Pimenta (coords.), Actas do Congresso Conquista e Romanização do Vale do Tejo. Cira Arqueologia 3: 385-403. Vila Franca de Xira, Câmara Municipal de Vila Franca de Xira.

Aquilué Abadias, X. y Bello Rodrigo, J. R. (2009): "Materiales arqueologicos de los contextos constructivos y de amortización”, en R. Ayerbe Vélez, T. Barrientos Vera y E. F. Palma García (eds.), El foro de Augusta Emerita: génesis y evolución de sus recintos. Anejos del Archivo de Español de Arqueologia LIII: 405-444. Madrid, Consejo Superior de Investigaciones Científicas.

Arruda, A. M. y Almeida, R. (1998): “As ânforas da Classe 32 da Alcáçova de Santarém (Campanhas de 1983-1991)". Conímbriga 37: 201-231.

Arruda, A. M. y Almeida, R. (2001): “Importação e consumo de vinho bético na colónia Romana da 
Scallabis (Santarém, Portugal)", en Actas do Congresso Internacional Ex Baetica Amphorae. Conservas y vino de la Bética en el Imperio Romano: Vol. 2, 703-715. Écija, Gráficas Sol.

Arruda, A. M. y Sousa, E. (2012): “Ânforas republicanas de Monte Molião (Lagos, Algarve, Portugal)". SPAL 22: 93-133. https://doi.org/10.12795/ spal.2013.i22.05

Arruda, A. M. y Viegas, C. (2016): “As ânforas altoimperiais de Monte Molião", en R. Járrega Domínguez y P. Berni Millet (eds.), Amphorae ex Hispania: paisajes de producción y consumo. Monografías Ex Officina Hispana III: Vol. I, 446-463. Tarragona, ICAC.

Arruda, A. M.; Viegas, C. y Bargão, $\quad$ P (2006a): "Ânforas lusitanas da Alcáçova de Santarém”, en Simpósio Internacional Produção e comércio de preparados piscícolas durante a Proto-História e a época Romana no ocidente da Península Ibérica. Homenagem a Françoise Mayet. Setúbal Arqueológica 13: 233-252. Setúbal, MAEDS.

Arruda, A. M.; Viegas, C.; Bargão, P. y Pereira, R. (2006b): “A importação de preparados de peixe em Castro Marim: da Idade do Ferro à época romana”, en Simpósio Internacional Produção e comércio de preparados piscícolas durante a Proto-História e a época Romana no ocidente da Península Ibérica. Homenagem a Françoise Mayet. Setúbal Arqueológica 13: 153-176. Setúbal, MAEDS.

Banha, C. (2006): As ânforas romanas de Idanha-a-Velha (Civitas Igaeditanorum). Dissertação de Mestrado em Pré-história e Arqueologia, Faculdade de Letras da Universidade de Lisboa. Inédita (Policopiado).

Bertrand, E. (2014): 46, Rue Victor Hugo, Place Ampère, 69002 Lyon. Rapport De Fouille D’archéologie Préventive. Ville de Lyon, Direction des Aaires Culturelles Service archéologique. Code d'opération $\mathrm{Pa}$ triarche 693822211371

Boaventura, R. y Banha, C. (2006): “Ânforas da região de Monforte: contributo para o conhecimento do comércio rural romano". O Arqueólogo Português 4:24: 369-399.

Bombico, S. (2016): Economia marítima da Lusitânia romana: exportação e circulação de bens alimentares. Tese de Doutoramento em Arqueologia, Universidade de Évora. Inédita (Policopiado). http://hdl. handle.net/10174/21051 (consultado en 12-12-2018).

Bugalhão, J. y Lourenço, S. (2006): “As ânforas romanas da Ilha da Berlenga”, en Simpósio Internacional Produção e comércio de preparados piscícolas durante a Proto-História e a época Romana no ocidente da Península Ibérica. Homenagem a Françoise Mayet. Setúbal Arqueológica 13: 279294. Setúbal, MAEDS.

Bugalhão, J. y Lourenço, S. (2011): “A ocupação romana da ilha da Berlenga". Revista Portuguesa de Arqueologia 14: 203-215.

Buraca, I. (2005): Civitas Conímbriga: Anforas romanas. Dissertação de Mestrado em Arqueologia, Faculdade de Letras da Universidade de Coimbra. Inédita.

Buraca, I. (2016): "Lusitanian amphorae en roman city of Conimbriga", en I. V. Pinto, R. R. Almeida y A. Martin (eds.), Lusitanian Amphorae: Production and Distribution. Roman and Late Antique Mediterranean Pottery 10: 231-240. Oxford, Archaeopress Series.

Calado, M.; Mataloto, R. y Pisco, M. (1999): "Povoamento Proto-histórico no Alentejo Central", en Actas do Congresso de Proto-História Europeia Centenário da morte de Martins Sarmento. Revista de Guimarães vol. especial, Vol. I: 363-386. Guimarães, Sociedade Martins Sarmento.

Cardoso, G. (1990): "O forno de ânforas de Muge”, en J. Alarcão. y F. Mayet (eds), Les amphores lusitaniennes typologie, production et commerce : 153165. Coimbra, Museu Monográfico de Conímbriga.

Cardoso, G. (2015): Estudio arqueológico de la villa romana de Freiria. Tesis Doctoral, Universidad de Extremadura. Inédita. (Policopiado). http://dehesa. unex.es/xmlui/handle/10662/3881 (consultado el 10-12-2018).

Cardoso, G.; Rodrigues, S. y Sepúlveda, E. (2006): “A olaria romana de Peniche", en Simpósio Internacional Produção e comércio de preparados piscícolas durante a Proto-História e a época Romana no ocidente da Península Ibérica. Homenagem a Françoise Mayet. Setúbal Arqueológica 13: 253278. Setúbal, MAEDS.

Cardoso, G.; Rodrigues, S.; Sepúlveda, E. y Ribeiro, I. (2016): "Production during the Principate en Peniche (Portugal). Raw Materials, Kilns and Amphora Typology", en I. V. Pinto, R. R. Almeida y A. Martin (eds.), Lusitanian Amphorae: Production and Distribution. Roman and Late Antique Mediterranean Pottery 10: 3-17. Oxford, Archaeopress Series.

Cardoso, J. L. (2011): Arqueologia no Concelho de Oeiras: do Paleolítico Inferior arcaico ao século XVIII. Oeiras, Câmara Municipal de Oeiras.

Carreras Monfort, C. y Morais R. (eds.) (2010): The Western Roman Atlantic Façade: a study of 
economy and trade In the Mar Exterior. From the Republic to the Principate. BAR International Series 2162. Oxford, Archaeopress Series.

Carreras Monfort, C. y Morais, R. (2011): "Las ánforas de Lucus Augusti”, en C. Carreras Monfort, R. Morais y E. González Fernández (coords.), Ánforas romanas de Lugo. Comercio romano en el Finis terrae. Trabalhos de Arqueoloxía $n^{\circ}$ 3: 33-78. Lugo, Concello de Lugo.

Dias, M. I.; Trindade, M. J.; Fabião, C.; Sabrosa, A.; Bugalhão, J.; Raposo, J.; Guerra, A.; Duarte, A. L. y Prudêncio, M. I. (2012): “Arqueometria e o estudo das ânforas lusitanas do Núcleo Arqueológico da Rua dos Correeiros (Lisboa) e de centros produtores do Tejo", en M. I. Dias y J. L. Cardoso (eds), Actas do IX Congresso Ibérico de Arqueometria. Estudos Arqueológicos de Oeiras 19: 57-70. Oeiras, Câmara Municipal de Oeiras.

Diogo, A. M. D. (1987): “Quadro tipológico das ânforas de fabrico lusitano". O Arqueólogo Português 4:5: 179-191.

Diogo, A. M. D. (2005): "Vestígios de um possível naufrágio ao largo da ilha do Farilhão", en Actas do Congresso A Presença Romana na Região Oeste: 103-107. Bombarral, Câmara Municipal do Bombarral.

Diogo, A. M. D. y Trindade, L. (1998): "Uma perspectiva sobre Tróia a partir das ânforas. Contribuição para o estudo da produção e circulação das ânforas romanas em território português". O Arqueólogo Português 4:16: 187-220.

Djaoui, D. y Quaresma, J. C. (2016): "Lusitanian Amphorae from the Dump Layer above the ArlesRhône 3 Shipwreck", en I. V. Pinto, R. R. Almeida y A. Martin (eds.), Lusitanian Amphorae: Production and Distribution. Roman and Late Antique Mediterranean Pottery 10: 357-368. Oxford, Archaeopress Series.

Fabião, C. (1989): Sobre as ânforas do acampamento romano da Lomba do Canho (Arganil). Lisboa, UNIARQ / INIC.

Fabião, C. (1998): “O vinho na Lusitânia: reflexões em torno de um problema arqueológico". Revista Portuguesa de Arqueologia 1:1: 169-198.

Fabião, C. (2008): "Las ánforas de Lusitania", en D. Bernal Casasola y A. Ribera i Lacomba (eds.), $\mathrm{Ce}$ rámicas hispanorromanas. Un estado de la cuestión: 725-745. Cádiz, Universidad de Cádiz.

Fabião, C. (2009): “A dimensão atlântica da Lusitânia: periferia ou charneira no Império Romano?", en J. G. Gorges, J. Encarnação, T. N. Basarrate y A.
Carvalho (eds.), Lusitânia Romana: entre o mito e a realidade. Actas da VI Mesa-Redonda Internacional sobre a Lusitânia Romana: 53-74. Cascais, Câmara Municipal de Cascais.

Fabião, C.; Guerra, A.; Almeida, J.; Almeida, R.; Pimenta, J. y Filipe, V. (2016): Marcas de ânforas romanas na Lusitânia (do Museu Nacional de Arqueologia de Lisboa ao Museo Nacional de Arte Romano de Mérida). Corpus Internationale des Timbres Amphoriques (Fascicule 19). Lisboa, Union Académique Internationale/Academia das Ciências de Lisboa. Centro de Arqueologia da Universidade de Lisboa.

Federico, R. (2007): "Contenitori da garum e consumi alimentari a villa Arianna di Stabiae: alcune considerazioni", en Actas del congreso Internacional CETARIAE. Salsas y salazones de pescado en Occidente durante la Antigüedad. B.A.R. International Series 1686: 255-270. Oxford, Archaeopress Series.

Fernández Fernández, A. (2013): O comercio tardoantigo no Noroeste Peninsular Unha análise da gallaecia sueva e visigoda a través do rexistro arqueolóxico. Serie Trivium 48. A Coruña, Editorial Toxosoutos.

Ferreira, M. A.; Faria, J. C. y Diogo, A. M. D. (1991): "Ânforas lusitanas do Cerrado do Castelo, Grândola". Conimbriga XXX: 105-108.

Filipe, V. (2008a): As ânforas do teatro romano de Lisboa. Dissertação de Mestrado em Pré-história e Arqueologia, Faculdade de Letras da Universidade de Lisboa. Inédita. (Policopiado).

Filipe, V. (2008b): "Importação e exportação de produtos alimentares em Olisipo: as ânforas romanas da Rua dos Bacalhoeiros". Revista Portuguesa de Arqueologia 11:2: 301-324.

Filipe, V. (2015): "As ânforas do teatro romano de Olisipo (Lisboa, Portugal): campanhas 2001-2006". SPAL 24: 129-163. https://doi.org/10.12795/ spal.2015i24.06

Filipe, V. (2016): "Haltern 70 (Western Lusitania)". Amphorae ex Hispania. Landscapes of production and consumption http://amphorae.icac.cat/amphora/haltern-70-western-lusitania (consultado en 15-12-2018).

Filipe, V. (2019): Olisipo, o grande porto romano da fachada atlâtica. Economia e comércio entre a República e o Principado. Tese de Doutoramento no ramo de História, especialidade de Arqueologia, Faculdade de Letras da Universidade de Lisboa. Inédita. http://hdl.handle.net/10451/38619.

Filipe, V.; Quaresma, J. C.; Leitão, M. y Almeida, R. R. (2016): "Produção, consumo e comércio de 
alimentos entre os séculos II e III d.C. em Olisipo: os contextos romanos da Casa dos Bicos, Lisboa (intervenção de 2010)", en R. Járrega Domínguez y P. Berni Millet (eds.), Amphorae ex Hispania: paisajes de producción y consumo. Monografías Ex Officina Hispana III: Vol. I, 423-445. Tarragona, ICAC.

Fonseca, C. (2015): Fundear e naufragar entre o Mediterrâneo e o Atlântico: o caso do arqueossítio Arade B. Dissertação de Mestrado, Faculdade de Ciências Sociais e Humanas, Universidade Nova de Lisboa. Inédita. http://hdl.handle.net/10362/18481 (consultado en 07-12-2018).

García Vargas, E.; Almeida, R. y González Cesteros, H. (2011): "Los tipos anfóricos del Guadalquivir en el marco de los envases hispanos del siglo I a.C. Un universo heterogéneo entre la imitación y la estandarización". SPAL 20: 185-283. http://dx.doi. org/10.12795/spal.2011.i20.12

Gomes, S.; Ponce, M. y Filipe, V. (2017): “A intervenção arqueológica no âmbito do Projecto de arquitectura Apartamentos Pedras Negras", en Actas do I Encontro de Arqueologia de Lisboa: 349-365. Lisboa, Câmara Municipal de Lisboa.

Guerra, A.; Schattner, T.; Fabião, C. y Almeida, R. (2003): "Novas investigações no santuário de Endovélico (S. Miguel da Mota, Alandroal): a campanha de 2002". Revista Portuguesa de Arqueologia 6:2: 415-479.

Hárshegyi, P. (2007), "Le anfore della villa romana di San Potito", en D. Gabler e F. Redő (eds.), Ricerche archeologiche a San Potito di Ovindoli e le aree limitrofe nell'antichitá e nel alto medioevo: 123-166. L'Aquila, Edizione Rea.

Mataloto, R. (2008): “O Castelo dos Mouros (Graça do Divor, Évora): a arquitectura "ciclópica" romana e a romanização dos campos de Liberalitas Iulia Ebora". Revista Portuguesa de Arqueologia 11:1: 123-147.

Mataloto, R. (2010): "Do campo ao Ager: povoamento e ocupação rural pré-romana do Alentejo Central e a sua romanização", en V. Mayoral Herrera y S. Celestino Pérez (coords.), Los paisajes rurales de la romanización: Arquitectura y explotación: 59-88. Madrid, La Ergástula.

Mataloto, R. y Angeja: (2015): "Soeiros revisitado: aspectos da romanização do território alto alentejano nos meados do séc. I a.C.”, en Actas del VII Encuentro de Arqueología del Suroeste Peninsular: 841-866. Aroche/Serpa, Câmara Municipal de Serpa, Ayuntamiento de Aroche.

Mataloto, R. y Roque, C. (2012): "Um regresso, de passagem, ao Castelo Velho de Veiros", en Actas do $V$
Encontro de Arqueologia do Sudoeste Peninsular: 669-685. Almodôvar, Câmara Municipal de Almodôvar.

Mataloto, R. y Roque, C. (2013): “Gentes de Endovélico: um primeiro balanço sobre a arqueologia da Rocha da Mina". Cadernos do Endovélico 1: 125-141.

Mataloto, R.; Williams, J. y Roque, C. (2014): “”... e dahí desceo a dar-lhe batalha...": a ocupação préromana e a romanização da região da Serra d'Ossa (Alentejo Central, Portugal)", en R. Mataloto, V. Mayoral Herrera y C. Roque (eds.), La gestación de los paisajes rurales entre la Prehistoria y el período romano. Formas de asentamiento y procesos de implantación. Anejos de Archivo Español de Arqueología LXX: 17-43. Mérida, Consejo Superior de Investigaciones Científicas.

Mataloto, R.; Williams, J. y Roque, C. (2016): “Amphorae at the origins of Lusitania: transport pottery from western Hispania Ulterior In Alto Alentejo", en I. V. Pinto, R. R. Almeida y A. Martin (eds.), Lusitanian Amphorae: Production and Distribution. Roman and Late Antique Mediterranean Pottery 10: 139-151. Oxford, Archaeopress Series.

Mateo Corredor, D. (2014): El comercio en Hispania Ulterior durante los siglos II a. C. y II d. C. Tráfico anfórico y relaciones mercantiles. Tesis Doctoral, Universidad de Alicante. Inédita. http://rua.ua.es/ dspace/handle/10045/56121.

Mauné, S. y Duperron, G. (2012): “Un lot de céramiques et d'amphores des années 10 ap. J.-C. mis au jour à Saint-Bézard (Aspiran, Hérault)"'. Revue Archéologique de Narbonnaise 45: 111-142. https:// doi.org/10.3406/ran.2012.1833

Mayet, F. y Schmitt, A. (1997): "Les amphores de São Cucufate (Beja)", en R. Étienne y F. Mayet, (eds.), Itinéraires Lusitaniens: 71-109. París, E. de Boccard.

Mayet, F. y Silva, C. T. (1998): L'atelier d'amphores de Pinheiro. Portugal. París, De Boccard.

Mayet, F. y Silva, C. T. (2002): L'atelier d'amphores d'Abul. París, De Boccard.

Mayet, F. y Silva, C. T. (2016): "Roman Amphora Production In the Lower Sado Region", en I. V. Pinto, R. R. Almeida y A. Martin (eds.), Lusitanian Amphorae: Production and Distribution. Roman and Late Antique Mediterranean Pottery 10: 59-71. Oxford, Archaeopress Series.

Morais, R. (2003): "Problemàtiques i noves perspectives sobre les àmfores ovóides tardo-republicanes. Les àmfores ovoides de producció Lusitana", en Culip VIII $i$ les àmfores Haltern 70. Monografies 
del Casc 5: 36-40. Girona, Museu d'Arqueología de Catalunya, Centre d'Arqueología Subaquàtica de Catalunya.

Morais, R. (2010): Ânforas", en J. Alarcão, P. Carvalho y A. Gonçalves (coords.), Castelo da Lousa - Intervenções Arqueológicas de 1997 a 2002. Studia Lusitana 5: 181-218. Mérida, Museo Nacional de Arte Romano.

Morais, R. y Fabião, C. (2007): "Novas produções de fabrico lusitano: problemáticas e importância económica", en Actas del congreso Internacional CETARIAE. Salsas y salazones de pescado en Occidente durante la Antigüedad. B.A.R. International Series 1686: 127-133. Oxford, Archaeopress Series.

Morais, R. y Filipe, V. (2016): “Ovoid Lusitan (Western Lusitania)". Amphorae ex Hispania. Landscapes of production and consumption http://amphorae.icac. cat/amphora/ovoid-lusitan-western-lusitania (consultado el 24-11-2018).

Morais, R.; Oliveira, C. y Araújo, A. (2016): “Lusitanian Amphorae of the Augustan Era and their Contents: Organic Residue Analysis", en I. V. Pinto, R. R. Almeida y A. Martin (eds.), Lusitanian Amphorae: Production and Distribution. Roman and Late Antique Mediterranean Pottery 10: 105-109. Oxford, Archaeopress Series.

Mota, N.; Grilo, C.; Almeida, R. y Filipe, V.(2017): "Apontamento crono-estratigráfico para a topografia histórica de Olisipo. A intervenção arqueológica na rua de São Mamede (Via Pública - 19), Santa Maria Maior, Lisboa”. Cira Arqueologia 5: 149-206.

Oliveira, C.; Morais, R. y Araújo, A. (2015): “Application of gas chromatography coupled with mass spectrometry to the analysis of ceramic containers of Roman Period - evidence from the Peninsular Northwest", en C. Oliveira, R. Morais y A. Morillo Cerdán (eds.), Chromatography and DNA analysis en Archaeology: 193-212. Esposende, Câmara Municipal de Esposende.

Paiva, M. (1993): Anforas romanas de castros da fachada atlântica do Norte de Portugal. Dissertação de Mestrado em Arqueologia, Faculdade de Letras da Universidade do Porto. Inédita.

Palazzo, P. (2013): Le anfore di Apani (Brindisi). Roma, Scienze e Lettere.

Parreira, J. (2009): As ânforas romanas de Mesas do Castelinho. Dissertação de Mestrado, Faculdade de Letras da Universidade de Lisboa. Inédita.

Pimenta, J. (coord.) (2015): O sítio arqueológico de Monte dos Castelinhos. Em busca de Ierabriga.
Vila Franca de Xira, Museu Municipal de Vila Franca de Xira.

Pimenta, J. (2017): "Em torno dos mais antigos modelos de ânfora de produção lusitana. Os dados do monte dos castelinhos - Vila Franca de Xira", en C. Fabião, J. Raposo, A. Guerra y F. Silva (eds.), Actas Seminário Internacional e Ateliê de Arqueologia Experimental. A Olaria Romana: 195-205. Lisboa, UNIARQ.

Pimenta, J.; Ferreira, M. y Cabrita, A. C. (2016): "The roman kilns at Estrada da Parvoíce, Alcácer do Sal (Portugal)", en I. V. Pinto, R. R. Almeida y A. Martin (eds.), Lusitanian Amphorae: Production and Distribution. Roman and Late Antique Mediterranean Pottery 10: 73-79. Oxford, Archaeopress Series.

Pimenta, J.; Henriques, E. y Mendes, H. (2012): $O$ Acampamento romano de Alto dos Cacos, Almeirim. Almeirim, Associação de Defesa do património Histórico e Cultural do Concelho de Almeirim.

Pimenta, J.; Mendes, H. y Henriques, E. (2014): “O Acampamento militar romano do Alto dos Cacos, Almeirim", en C. Fabião y J. Pimenta (coords.), Actas do Congresso Conquista e Romanização do Vale do Tejo. Cira Arqueologia 3: 256-292. Vila Franca de Xira.

Pimenta, J. y Mendes, H. (2014): "Monte dos Castelinhos - Vila Franca de Xira. Um sítio singular para o estudo da romanização do Vale do Tejo", en R. Mataloto, V. Mayoral Herrera y C. Roque (eds.), La gestación de los paisajes rurales entre la Prehistoria y el período romano. Formas de asentamiento y procesos de implantación. Anejos de Archivo Español de Arqueología LXX: 125-142. Mérida, Consejo Superior de Investigaciones Científicas.

Pimenta, J.; Sepúlveda, E.; Faria, J. C. y Ferreira, M. (2006): "Cerâmicas romanas do lado ocidental do castelo de Alcácer do Sal, 4: ânforas de importação e de produção lusitana". Revista Portuguesa de Arqueologia 9:2: 299-316.

Pimenta, J.; Sepúlveda, E. y Ferreira, M. (2015): "Acerca da dinâmica económica do porto de Urbs Imperatoria Salacia: o estudo das ânforas". Cira Arqueologia 4: 151-170.

Pinto, I. V. y Lopes, C. (2006): “Ânforas das villae romanas alentejanas de São Cucufate (Vila de Frades, Vidigueira), Monte da Cegonha (Selmes, Vidigueira) e Tourega (Nossa Senhora da Tourega, Évora)", en Simpósio Internacional Produção e comércio de preparados piscícolas durante a Proto-História e a época Romana no ocidente da Península Ibérica. 
Homenagem a Françoise Mayet. Setúbal Arqueológica 13: 197-224. Setúbal, MAEDS.

Pinto, I. V.; Magalhães, A. y Brum: (2016): “Un depotoir du ve siecle dans l'officine de salaisons 1 de Troia (Portugal) ", en Rei Cretarice Romance Favtorvm Acta 42: 397-406.

Prudêncio, M. I.; Dias, M. I. y Ponte, S. (2005): “Amphorae en Sellium from the first century to the fifth century AD: importation and regional production", en M. I. Prudêncio, M. I. Dias y J. C. Waerenborgh (eds.), Understanding people through their pottery. Proceedings of the 7th European Meeting on Ancient Ceramics (EMAC'03). Trabalhos de Arqueologia 42: 201-209. Lisboa, Instituto Português de Arqueologia.

Quaresma, J. C. (2005), “Ânforas romanas provenientes da pesca de arrasto no Tejo, depositadas no $\mathrm{Mu}$ seu Municipal de Vila Franca de Xira". Revista Portuguesa de Arqueologia 8.2: 403-428.

Quaresma, J. C. y Calais, C. (2005): "S. Pedro (Coruche): novos dados para o processo de romanização do Vale do Sorraia na época augustana e júlio-cláudia”. Revista Portuguesa de Arqueologia 8:2: 429-447.

Remesal Rodríguez, J. (2010): "De Baetica a Germania, consideraciones sobre la ruta y el comercio atlántico en el Imperio Romano", en F. Marco Simón, F. Pina Polo y J. Remesal Rodríguez (eds.), Viajeros, peregrinos y aventureros en el mundo antiguo: 147-160. Barcelona, Universitat de Barcelona.

Silva, C.T. (1996): "Produção de ânforas na área urbana de Setúbal: a oficina romana do Largo da Misericórdia", en Ocupação romana dos estuários do Tejo e do Sado. Actas das Primeiras Jornadas sobre Romanização dos Estuários do Tejo e do Sado: 43-54. Seixal, Câmara Municipal Lisboa, Dom Quixote.

Silva, C. T. y Coelho-Soares, A. (2014): "Preexistências de Setúbal. A ocupação da Época Romana da
Travessa de João Galo, nº. 4-4B”. Setúbal Arqueológica 15: 305-338.

Silva, R. B. (2014): "Intervenção Arqueológica Urbana de 1993 na Fundação Ricardo Espirito Santo Silva/Largo das Portas do Sol (Lisboa): as evidências do período romano", en C. Fabião y J. Pimenta (coords.), Actas do Congresso Conquista e Romanização do Vale do Tejo. Cira Arqueologia 3: 178-199. Vila Franca de Xira, Câmara Municipal de Vila Franca de Xira.

Silva, R. B. (2015): "Um contexto alto-imperial da Rua dos Remédios, Lisboa”, en J. C. Quaresma y J. Marques (coords.), Contextos estratigráficos na Lusitania (do Alto Império à Antiguidade Tardia). Monografias 1: 41-67. Lisboa, AAP.

Silva, R. B.; Filipe, V. y Almeida, R.(2016): “JulioClaudian lusitanian amphorae: a perspective on selected contexts from Olisipo (Lisbon, Portugal)", en I. V. Pinto, R. R. Almeida y A. Martin (eds.), Lusitanian Amphorae: Production and Distribution. Roman and Late Antique Mediterranean Pottery 10: 153-166. Oxford, Archaeopress Series.

Soeiro, T. (1984): Monte Mozinho: apontamentos sobre a ocupação entre Sousa e Tâmega em época Romana. Boletim Municipal de Cultura 3:1. Penafiel, Câmara Municipal de Penafiel.

Sousa, L.; Nunes, M. y Gonçalves, C. (2006): “O vinho na antiguidade clássica. Alguns apontamentos sobre Lousada". Oppidum 1: 69-85.

Tchernia, A. (1986): Le vin de l'Italie romaine. Essai d'histoire économique d'après les amphores. París, De Boccard.

Trindade, L. y Diogo, A. M. D. (1998): “Ânforas romanas provenientes do castro de Chibanes". Al-Madan 2:7: 172-173.

Viegas, C. (2011): A ocupação romana do Algarve. Estudo do povoamento e economia do Algarve central e oriental no período romano. Estudos \& Memórias 3. Lisboa, UNIARQ. 